\title{
Imidazole and Triazole Coordination Chemistry for Antifouling Coatings
}

\author{
Markus Andersson Trojer, ${ }^{1}$ Alireza Movahedi, ${ }^{1}$ Hans Blanck, ${ }^{2}$ and Magnus Nydén ${ }^{1,3}$ \\ ${ }^{1}$ Applied Surface Chemistry, Department of Chemical and Biological Engineering, \\ Chalmers University of Technology, 41296 Göteborg, Sweden \\ ${ }^{2}$ Department of Biological and Environmental Sciences, University of Gothenburg, 40530 Göteborg, Sweden \\ ${ }^{3}$ Ian Wark Research Institute, University of South Australia, Adelaide, SA 5001, Australia
}

Correspondence should be addressed to Markus Andersson Trojer; markus.andersson@chalmers.se

Received 29 April 2013; Accepted 9 July 2013

Academic Editor: Suleyman Goksu

Copyright (C) 2013 Markus Andersson Trojer et al. This is an open access article distributed under the Creative Commons Attribution License, which permits unrestricted use, distribution, and reproduction in any medium, provided the original work is properly cited.

\begin{abstract}
Fouling of marine organisms on the hulls of ships is a severe problem for the shipping industry. Many antifouling agents are based on five-membered nitrogen heterocyclic compounds, in particular imidazoles and triazoles. Moreover, imidazole and triazoles are strong ligands for $\mathrm{Cu}^{2+}$ and $\mathrm{Cu}^{+}$, which are both potent antifouling agents. In this review, we summarize a decade of work within our groups concerning imidazole and triazole coordination chemistry for antifouling applications with a particular focus on the very potent antifouling agent medetomidine. The entry starts by providing a detailed theoretical description of the azole-metal coordination chemistry. Some attention will be given to ways to functionalize polymers with azole ligands. Then, the effect of metal coordination in azole-containing polymers with respect to material properties will be discussed. Our work concerning the controlled release of antifouling agents, in particular medetomidine, using azole coordination chemistry will be reviewed. Finally, an outlook will be given describing the potential for tailoring the azole ligand chemistry in polymers with respect to $\mathrm{Cu}^{2+}$ adsorption $^{2}$ and $\mathrm{Cu}^{2+} \rightarrow \mathrm{Cu}^{+}$reduction for antifouling coatings without added biocides.
\end{abstract}

\section{Introduction}

A major problem for the shipping industry is fouling of marine organisms, such as algae, mussels, and barnacles on ship hulls [1-5]. As the ship moves through the water, the hull is subjected to form drag and skin friction drag. Since fouling increases the surface roughness, the skin friction drag is increased, which subsequently results in increased fuel consumption and reduced manoeuvrability [3]. Traditional countermeasures against marine fouling are coatings containing antifouling toxicants that have had severe environmental consequences on marine ecosystems. The most wellknown examples are organometallic paint systems (comprising lead, arsenic, mercury, etc.) which met the market in the early 1960s. The notorious tributyltin self-polishing coating (TBT-SPC) was developed in the 1970s $[1,6]$. The reason for the success of the TBT-SPC paints is that the rate of release can be controlled on a molecular level. Generally, these paints are based on acrylic or methacrylic copolymers. The active substance (TBT) is covalently attached to the carboxylic group of the polymer, which is hydrolytically instable in slightly alkaline conditions (as in seawater) $[1,4,6]$. Toxic copper pigment is also included in the TBT-SPC paint systems, which in combination with TBT, provides protection against the entire spectrum of fouling organisms since some algae are tolerant to TBT but not to copper and vice versa [7]. As the use of TBT containing paints increased, marine life in the vicinity of harbours and marinas was severely affected $[8,9]$. The hazardous nature of TBT for the marine environment is ascribed to its weakening of fish immune systems, causing imposex and sterility in female gastropods (at such low concentration as $1 \mathrm{ng} / \mathrm{L}$ ) as well as its bioaccumulative properties in mammals $[1,4,6]$. Starting with TBT ban for pleasure craft in France 1982, TBT-containing paint systems were successively phased out in the 1990s 
and finally banned by IMO (the International Maritime Organization) $[10,11]$.

A number of tin-free alternatives have been developed due to the restrictive legislation regarding TBT paints. These can crudely be divided into biocide-release and biocide-free antifouling systems. Biocide-free approaches are dominated by paint systems called foul-release coatings. The antifouling mechanism lies in the low surface energy and smoothness of the coating. The binders in these coatings are silicone polymers, for example, PDMS (polydimethylsiloxane) and to some extent fluoropolymers, with both possessing very low surface energy.

In tin-free SPC paints, tin is replaced by other elements such as copper, zinc, and silicon. Even though the side group of a few tin-free SPC paint binders also possess biocidal properties, no alternative is nearly as effective as TBT $[4,6]$. To provide full and long-term fouling protection, it is now necessary to add other biocides, so called boosters, generally in combination with copper. The most frequently employed boosters are conventional agrochemicals, some of which, for example, irgarol, have been under scrutiny due to low rate of biodegradation as well as toxicity towards nontarget organisms $[1,4,6,10-18]$. Since also the use of copper has been under debate recently, a number of other pigments are used such as $\mathrm{Zn}$ (II), Fe(III), and Ti(IV) oxides [1, 3, 4, 6].

A generic problem with tin-free SPC paints is premature leakage of the booster biocides [3]. These are not anchored to the binder, as TBT is, and are hence subjected to free diffusion within the paint matrix. The immediate consequence of premature leakage is loss of antifouling effect prior to the hydrolysis-dependent lifetime of the coating.

A lot of research and development has been conducted on SPC paints from an environmental perspective. For instance, the antifouling substances secreted by marine organism, that is, natural biocides, have recently attracted attention from the scientific community. The antifouling mechanisms of these natural biocides are generally much more intricate and specific compared to those of conventional booster biocides $[3,4,6]$. Some examples of natural antifoulants are worth mentioning. Furanon, originating from red seaweed, is for instance 100 times more effective than TBT as antifoulant against barnacle [3]. Bufalin (a toad poison) is for example, considered to be 100 times more toxic than TBT and 6000 times more efficacious against barnacles [6]. Most substances are found in the phyla Porifera (sponges), Algae, Cnidaria (e.g., corals, sea anemones, and hydroids), Echinodermata (e.g., sea urchins), Bryozoa (moss animals), and bacteria [3, 6]. Many antimicrobial substances are based on five-membered aromatic heterocycles such as Seanine and OIT (see Scheme 1). Moreover, triazole-based biocides represent a wide spectrum of in particular antifungals such as fluconazole and itraconazole (see Scheme 1) [19-27]. The imidazole fungicide clotrimazole (see Scheme 1) used as human and veterinary pharmaceutical has been found in the marine environment at concentrations affecting sterol metabolism in marine microalgal communities [28]. The interdisciplinary research program Marine Paint [2], in which our group has been a part, has since 2001 been investigating the substance medetomidine [29] (see Scheme 1) which is based on imidazole for antifouling purposes [30-32]. Medetomidine is exceptionally efficient against fouling barnacles [33], which is one of the most problematic foulants in the north Atlantic, yet, without seriously affecting nontarget organisms [34-37].

In this review, we will summarize a decade of research concerning azole (primarily imidazole) coordination chemistry for antifouling coatings. The work spans a variety of chemistry disciplines including molecular modelling $[38,39]$, surface and colloidal chemistry [40-43], controlled release [30, 31, 40-42, 44-46], coordination chemistry [39, 40, 47], polymer synthesis [47-50], and material science [39, 47]. Some references from other groups will be provided; however, it is important to note that very few studies have addressed azole coordination for antifouling purposes, and the area is still rather unexplored. The azole coordination approaches implemented by us with respect to antifouling coatings can be divided into three main categories: (1) antifoulant immobilization, (2) triggered release and (3) $\mathrm{Cu}^{2+} / \mathrm{Cu}^{+}$mediated antifouling as described later.

1.1. Antifoulant Immobilization. Booster biocides, including the azole-based molecules already mentioned, are typically small molecules which are molecularly dispersed in the antifouling paint $[3,51]$. As a consequence, the biocides leach out from the coating within a couple of weeks (diffusive release from thin coatings $\sim 100 \mu \mathrm{m}$ ) [52]. This results in a premature loss of fouling protection which is a severe problem since the desired lifetime of a marine coating is $\sim 5$ years [ 3 , 4]. However, when the biocides are immobilized on macromolecules or colloids (with negligible diffusion coefficients given there large sizes), the effective diffusion coefficient will be reduced by the magnitude of the stability constant for immobilization [53]. We have explored the possibility to immobilize the very efficient antifoulant medetomidine on polymers and nanoparticles by exploiting the strong and specific coordination chemistry of the molecule's imidazole moiety. This is treated in Section 5.

1.2. Triggered Release and Imidazole-Cu${ }^{2+}$ Coordination. The approach discussed in the previous section is obviously only applicable for azole-based biocides/antifoulants. Most booster biocides do not contain a strong ligand moiety for coordination chemistry. We have therefore developed more generic release systems based on polymeric poly(methyl methacrylate) microcapsules [52-60] with some novel advances involving ultrathin polyelectrolyte multilayers for sustained release [53, 60-66]. However, in order to maintain protection against fouling, it is important that the biocide concentration reaches high enough concentrations at the coating surface (see Scheme 2). Consequently, it would be beneficial if the release of the antifouling substance could be triggered by some physical or chemical parameters at the hull-water interface. We have explored the possibility to achieve triggered release by incorporating salt in the otherwise rather hydrophobic microcapsule shell using azole coordination chemistry. The salt will initiate swelling of the shell by increasing the free volume of the polymer [54] and hence 

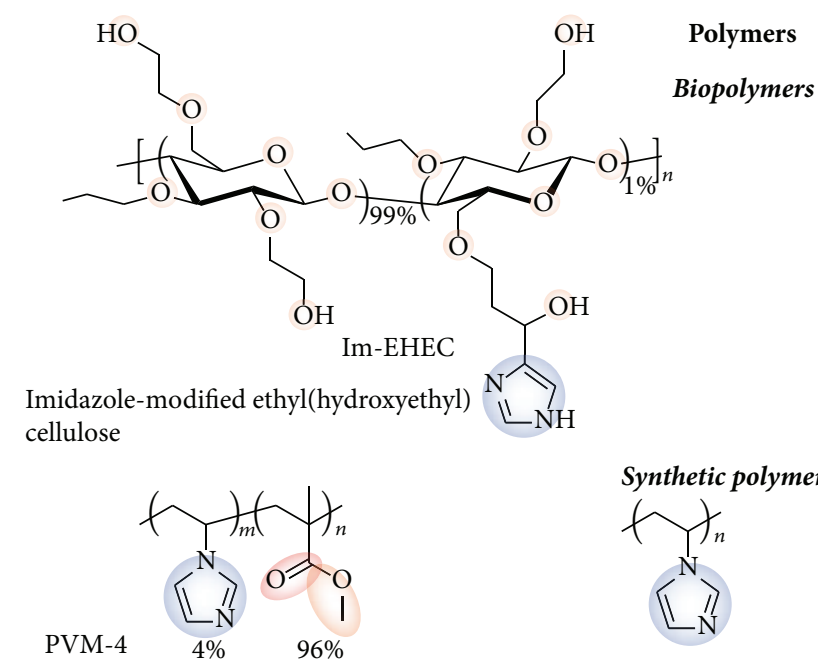

PVM-44 $44 \% \quad 56 \%$

Poly(1-vinylimidazole-co-methylmethacrylate)

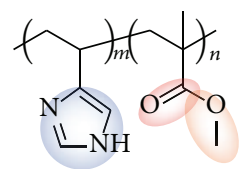

P4VM-4 $\quad 4 \% \quad 96 \%$

Poly(4-vinylimidazole-co-methylmethacrylate)

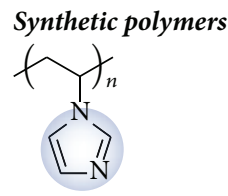

$\mathrm{P}(1-\mathrm{VIm})$

Poly(1-vinylimidazole) Polystyrene- $b$-poly(ethylene-co-butylene)- $b$-polystyrene

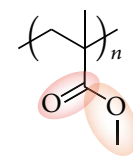

PMMA

Polymethylmethacrylate

\section{PSEBS}

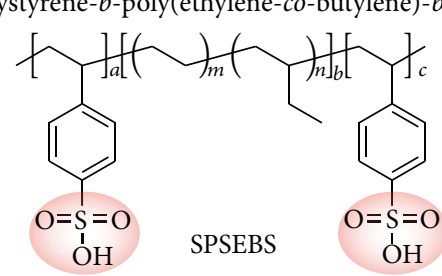

Sulphonated polystyrene- $b$-poly(ethylene-co-

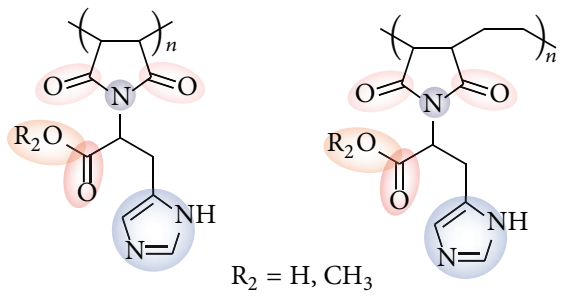

PHMI

$\mathrm{P}(\mathrm{E}-$ alt-HMI)

Poly(maleoyl-histidine) Poly(ethylene-alt-N-histidyl maleimide) butylene)- $b$-polystyrene

\section{Monomeric imidazoles and five-membered nitrogen heterocyclic antifouling biocides}

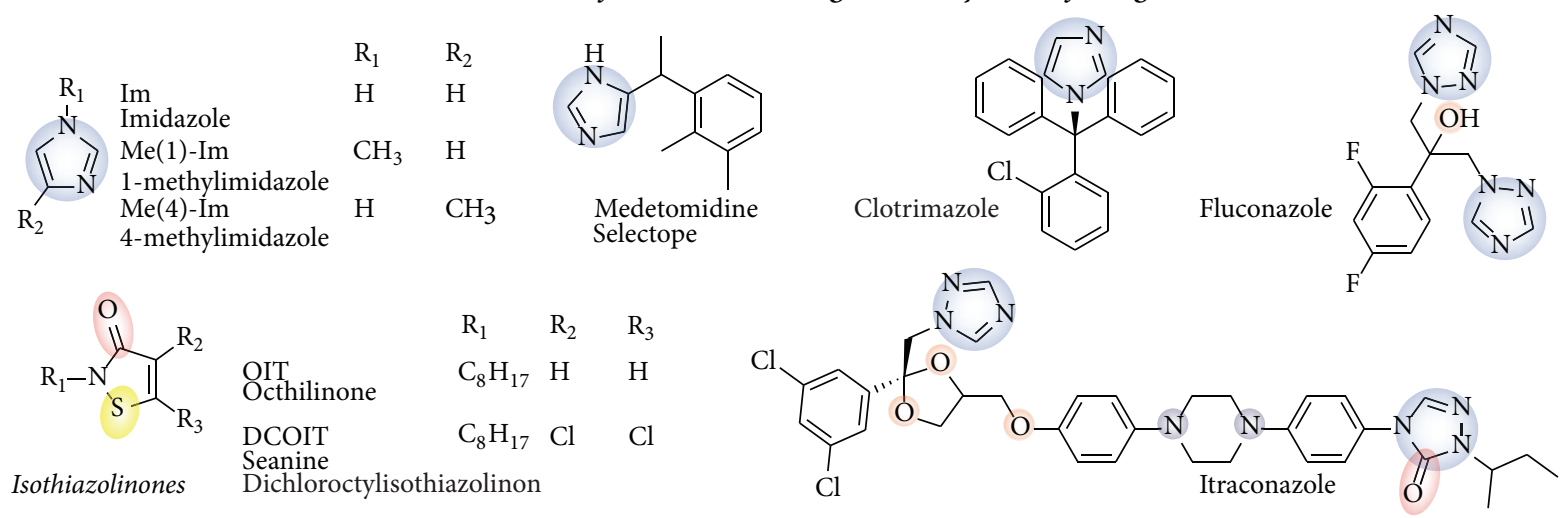

Scheme 1: Molecular structure, names, and abbreviations of polymers used for azole coordination and low molecular weight imidazole containing substances and five-membered nitrogen heterocyclic biocides investigated in this review. Potential nitrogen coordinating borderline ligands (imidazole, triazole) or hard ligands (amines), oxygen coordinating hard ligands, and sulphur coordinating soft ligands are marked with blue, purple, red, and yellow, respectively. Weak ligands such as organic halides have not been marked.

trigger the release from the microcapsule shell as a function of contact with water or moisture (see Scheme 2). The functionalization of polymers with azoles (mainly imidazole) is treated in Section 3, and the material properties and water sorption with respect to the presence of metal ions (in particular $\mathrm{Cu}^{2+}$ and $\mathrm{Zn}^{2+}$ ) in the polymer matrix are treated in Section 4.

The azole coordination has also been used to trigger the release of medetomidine. This is treated in Section 5.1.
1.3. Towards $\mathrm{Cu}^{2+} / \mathrm{Cu}^{+}$Catalysis in Novel Biocide-Free Marine Coatings. Copper is a potent antifouling biocide for in particular marine organisms $[67,68]$. Yet, copper is also a trace element and constitutes an essential part of many enzymes where redox reactions are the central function. However, excess copper concentrations are lethal for the organism since vital biological processes (disruption of cell homeostasis such as $\mathrm{pH}$ balance, membrane potential, and osmosis) are affected via the inactivation of enzymes and by the precipitation 


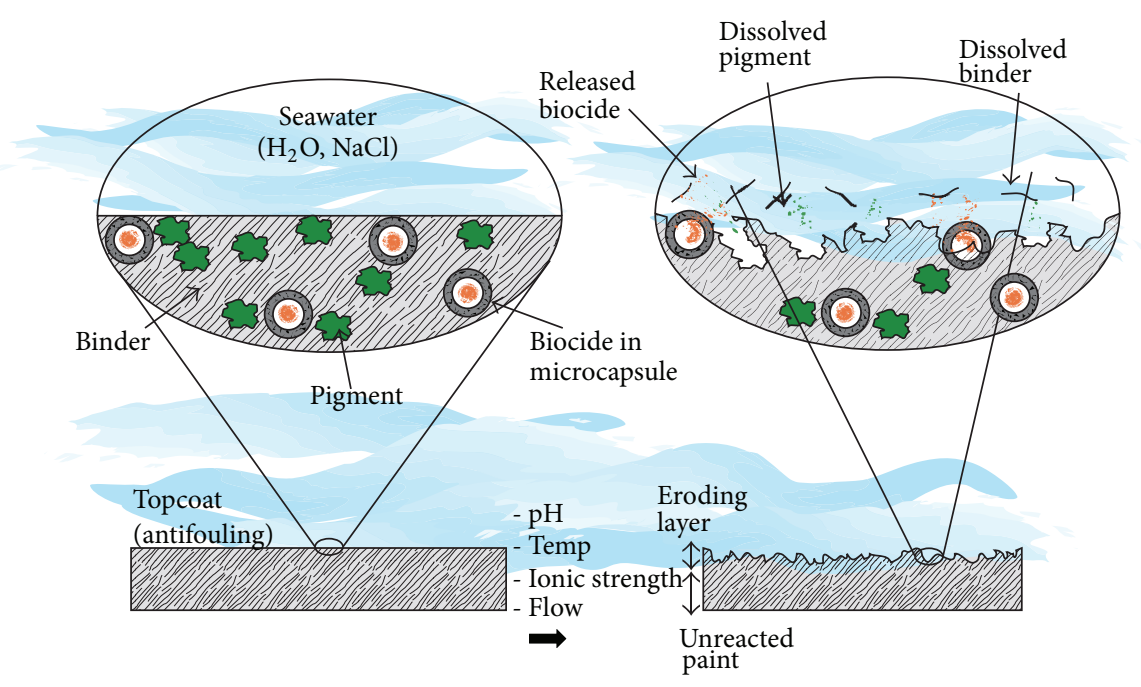

(a)

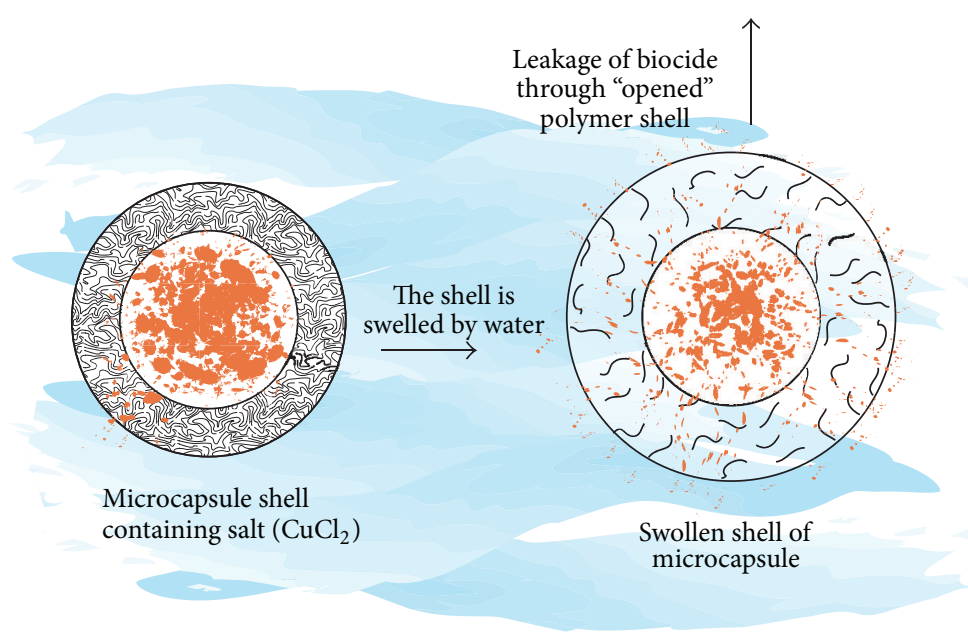

(b)

Scheme 2: Triggered release mechanism for (a) a self-polishing paint and (b) containing microcapsules.

cytoplasmic proteins into metal-protein aggregates $[69,70]$. Many studies are pointing towards the fact that copper crosses the biological membranes as $\mathrm{Cu}^{+}$which is subsequently the biologically most active oxidation state [69]. However, $\mathrm{Cu}^{+}$is unstable in an aqueous environment and disproportionates to $\mathrm{Cu}^{2+}$ and $\mathrm{Cu}^{0}[71,72]$. Moreover, only free ions of $\mathrm{Cu}^{2+}$ and $\mathrm{Cu}^{+}$are considered to be bioavailable [73-75]. A lot of recent focus in the catalysis and microbiology community is addressing $\mathrm{Cu}^{+}$stabilization by altering the $\mathrm{Cu}^{2+} / \mathrm{Cu}^{+}$ redox potential via the proper choice of ligand environment, both with respect to chemistry and geometry (see Section 2) [76-79]. Here, the ligand environment in copper proteins, including both the $\mathrm{Cu}(\mathrm{I})$ [77-79] and the $\mathrm{Cu}(\mathrm{II})$ [79-94] oxidation statse, is a continuous source of inspiration.

Encouraged by our findings concerning azole- $\mathrm{Cu}^{2+}$ coordination mentioned in the previous Section and recent advances in $\mathrm{Cu}^{2+} / \mathrm{Cu}^{+}$stabilization, we have developed a generic concept of biocide-free antifouling coatings. By incorporating azole-type ligands in the antifouling coating, the pool of free and sequestered $\mathrm{Cu}^{2+}$ in the marine environment may be absorbed. It is important that the interaction is strong enough since a large fraction of the dissolved copper in the sea is associated with organic ligands. Typically, weak ligands are considered to have stability constants of the order $10^{9}$ and strong ligands of the order $10^{13}$ [73-75]. However, this concept is still feasible given the fact that azole-type ligands have stability constants for copper coordination ranging between $10^{14}-10^{20}$ depending on chelate properties and chemistry as discussed in Sections 2 and 6 and the references within. Furthermore, regarding the antifouling coating, the presence of strongly $\mathrm{Cu}^{+}$stabilizing ligands, for example, nitriles and sulphur-containing ligands, may catalyse the reduction of $\mathrm{Cu}^{2+}$ to $\mathrm{Cu}^{+}$. This will produce high concentrations of $\mathrm{Cu}^{2+}$ and $\mathrm{Cu}^{+}$, both of which are efficient antifouling agents 
$[67,68]$, at the coating interface without any net addition of biocides to the environment (see Scheme 3). The azole specificity towards $\mathrm{Cu}^{2+}$ is treated in Section 4.1, and the $\mathrm{Cu}^{+}$ stabilization including our on-going work with the triazole ligand is briefly discussed in Section 6.2.

\section{Theoretical Considerations of Imidazole and Triazole Coordination Chemistry}

In this work, the coordination of azole ligands (mainly imidazole) by $\mathrm{Cu}^{2+}, \mathrm{Cu}^{+}$, and $\mathrm{Zn}^{2+}$ ions has been investigated as presented in Scheme 4. It is therefore pertinent to describe the fundamentals for the strong interaction between the previously mentioned species. In the following subsections, the azole coordination chemistry will be briefly reviewed in terms of coordination geometry, molecular orbitals and electronic structure, covalency, aromaticity, and so forth.

2.1. HSAB Principles and $\sigma$-Interaction. The strong metalligand bonding between the metal ions $\mathrm{Zn}^{2+}, \mathrm{Cu}^{+}$(diamagnetic $\mathrm{d}^{10}$ full $\mathrm{d}$-shell configuration), $\mathrm{Cu}^{2+}$ (paramagnetic $\mathrm{d}^{9}$ configuration), and the imidazole or triazole ligand (see Scheme 5) may be qualitatively explained by HSAB (Hard Soft Acid Base) principles [95, 98, 99]. To begin with, only the electron lone pair donation from the base (ligand) to the acid (metal), $\sigma$-bonding, will be considered.

Hard bases preferentially bond to hard acids via ionic bonding, whereas soft bases favourably bond to soft acids via covalent bonding $[98,99]$. In the ligand field depiction (see Scheme 7) this implies that the energy levels of the metal (M) and ligand (L) orbitals (the $\mathrm{d} \sigma$ - and $\sigma$-levels) will be similar $[100,101]$. The ensuing M-L molecular orbitals will have almost equivalent proportions of metal and ligand character, respectively, and the electrons spend their time at the metal and ligand equally [100]. Ionic bonding denotes large orbital energy differences with essentially no electron sharing [98-100].

Hard acids and bases are small, hard to polarize with low and high electronegativity, respectively $[98,99]$. They possess large HOMO-LUMO (Highest Occupied Molecular Orbital, Lowest Unoccupied Molecular Orbital) gaps, favouring ionic bonding [100]. Soft acids and bases are large and polarizable with intermediate electronegativity and with small HOMOLUMO gaps $[98,99]$. Note that $\mathrm{Cu}^{+}$is considered a soft acid and that triazole is softer than imidazole. A high oxidation state usually renders the transition metal hard, whereas the soft has low oxidation state $(\leq 2)[100]$. With regard to bases, unsaturation usually makes them softer [99]. For regular $\sigma$ donors, the coordinate bond may be viewed as polar covalent, especially with regards to borderline acids and bases (see below) $[99,100]$. The selectivity of different metal-ligand pairs in polymers is treated in Section 4.1.

2.2. $\pi$-Interaction. $\pi$-bonding is another important interaction (besides $\sigma$-bonding) in transition metal complexes (see Schemes 5 and 7) [100]. Ligands with more than one lone pair, labelled $\pi$-donors or $\pi$-bases (see Schemes 5 and 7 ), for example, $\mathrm{Cl}^{-}$and $\mathrm{RO}^{-}$, may donate additional electron density to a metal $d$ orbital ( $\pi$-acid) of proper symmetry (see Scheme $7, \pi$-bond) [100]. This interaction is typically considered hard and destabilizes the metal d-orbitals but will be favourable for hard, electropositive (especially $\mathrm{d}^{0}$ ) transition metals [100]. Certain ligands, labelled $\pi$-acceptor or $\pi$-acid have low-lying vacant LUMOs of proper symmetry with regard to the metal $\mathrm{d} \pi$-orbitals ( $\pi$-base) susceptible for metal to ligand $\pi$-bonding (back donation), an interaction typically considered soft. This interaction may be favourable since it alleviates the metal of some electron density in the coordination compound. For unsaturated ligands, the antibonding $\pi^{*}$-orbital typically accepts electron from the metal $\mathrm{d} \pi$-orbitals, which is favourable for electron-rich metals in low oxidation states with high energy d-orbitals that are basic in character [100].

2.3. Coordination Geometry. Imidazole is coordinated by $\mathrm{Cu}^{2+}$ in an essentially square planar geometry $\mathrm{Cu}(\mathrm{Im})_{4}{ }^{2+}$. $\mathrm{X}_{2}^{-}$, similar to pyridine (see Schemes 6(a) and 6(c)), with the imidazole rings occupies coplanar positions with respect to $\mathrm{Cu}$ (II) [95]. This favours $\pi$-interaction between the imidazole ring orbitals and metal $\mathrm{d} \pi$ orbitals and locates the electron hole in a distinctly separated orbital (see Scheme 6(a)) $[79,95]$. In the case of $\mathrm{Zn}^{2+}$ or $\mathrm{Cu}^{+}$, tetrahedral geometry is frequently encountered (common for $\mathrm{d}^{10}$ metals [101]), $\mathrm{Zn}(\mathrm{Im})_{4}{ }^{2+} \cdot \mathrm{X}_{2}^{-}$(see Scheme $7(\mathrm{~b})$ ). Octahedral geometry (see Scheme $5(\mathrm{c})$ ), $\mathrm{Zn}(\mathrm{Im})_{6}{ }^{2+} \cdot \mathrm{X}_{2}^{-}$, is also possible for $\mathrm{Zn}$ (II) but not for $\mathrm{Cu}(\mathrm{I})$. The coordination is less dependent on electronic factors for $\mathrm{Zn}$ (II) and more on steric factors in contrast to $\mathrm{Cu}^{2+}$ complexes $[95,101]$. As an example, $\mathrm{Zn}^{2+}$ with $\mathrm{Cl}^{-}$as counterion coordinates unsubstituted imidazole in octahedral geometry of $\mathrm{O}_{h}$ symmetry $\left[\mathrm{Zn}(\mathrm{Im})_{6}\right]^{2+}$ (see Section 6.1) [38]. However, the addition of a methyl group at position 1 or 4 on the imidazole ring, which gives a slight steric hindrance, results in the formation of pseudotetrahedral complexes $\left[\mathrm{Zn}(\mathrm{Me}-\mathrm{Im})_{2} \mathrm{Cl}_{2}\right]$ of $\mathrm{C}_{2 v}$ symmetry, even at large excess of imidazole ligands [38]. It should be noted that the nature of the counterion has an effect on the type of complex formed and that octahedral $\left(O_{h}\right.$ symmetry) and tetrahedral ( $T_{d}$ symmetry) complexes of $\mathrm{Zn}^{2+}$ and methylated imidazoles have been reported [95].

The coordination geometries for triazole ligands are more complicated. Since triazole is bidentate, with the possibility to bind to two metal centers, the coordination usually results in polymeric $(1 \mathrm{D}, 2 \mathrm{D}$ or $3 \mathrm{D})$ structures [102-105]. This is a popular method to produce metal-organic frameworks which is also possible for imidazole ligands at sufficiently high $\mathrm{pH}$ $[38,95]$. However, this is outside the scope of this review and will not be further treated. Mononuclear coordinate complexes comprising triazole ligands do exist provided that the triazole is substituted with sufficiently bulky groups. In these situations, the triazole displays the same type of coordination geometries as the imidazole ligand [102-104] (see Scheme 6).

2.4. Comparison with Other Nitrogen Ligands. Azoles and other unsaturated nitrogen ligands, such as pyridine, are categorized as borderline bases, while $\mathrm{Cu}^{2+}$ and $\mathrm{Zn}^{2+}$ are borderline acids in contrast to $\mathrm{Cu}^{+}$which is soft $[95,98,99]$. 


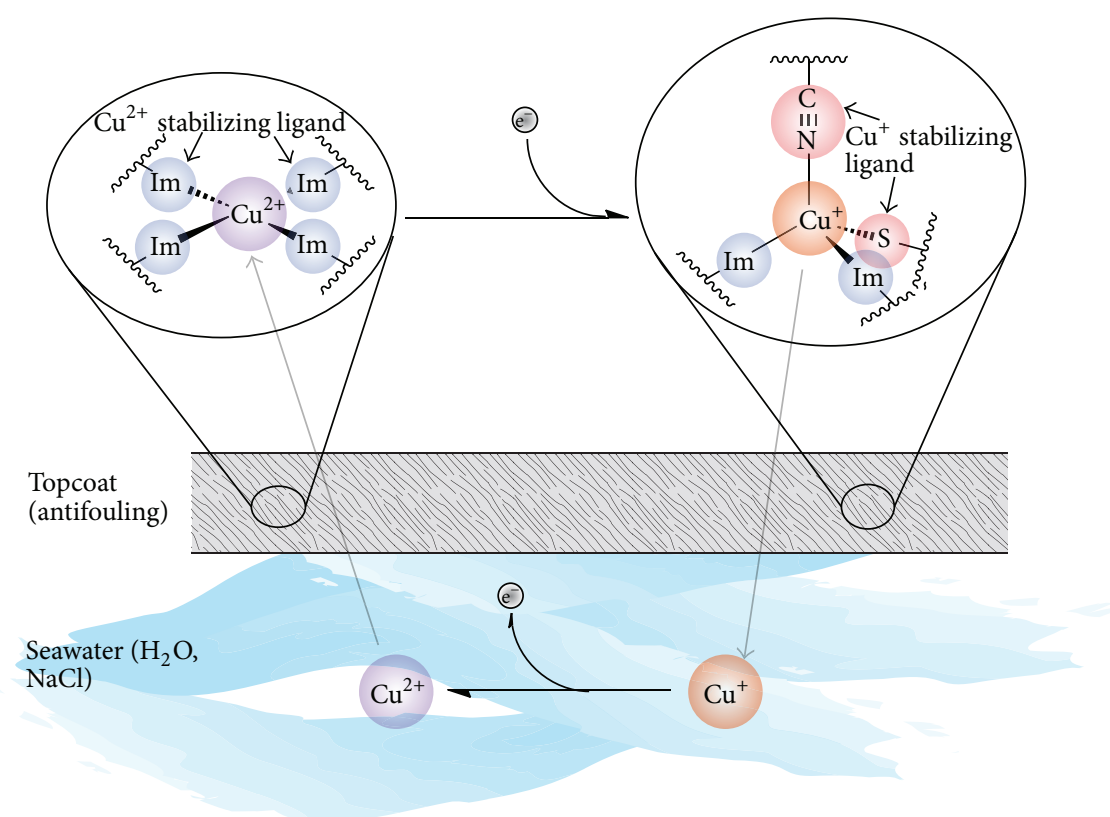

Scheme 3: Mechanism for ligand-mediated absorption and redox reaction.
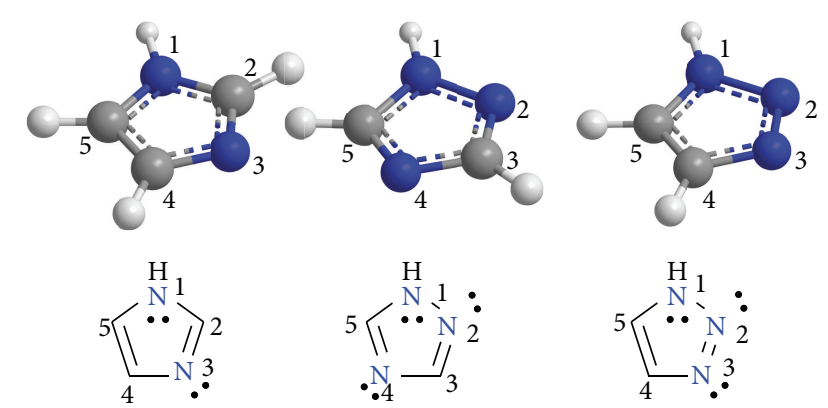

SCHeme 4: Structure and numbering of the imidazole 1,2,4-triazole and 1,2,3-triazole. $\mathrm{N}_{1}$ is labelled pyrrole nitrogen and $\mathrm{N}_{3}$ (imidazole) and $\mathrm{N}_{2} / \mathrm{N}_{4}$ (triazole) are labelled pyridine nitrogen. Note that $\mathrm{N}_{1}$ is also $\mathrm{sp}^{2}$ hybridized and the free electron pair is donated to the ring $\pi$-orbital system in order to obtain aromaticity. The lone electron pair of $\mathrm{N}_{3}$ is, however, free rendering of this nitrogen basic and the predominant site for coordination [95].

Consequently, these borderline acid-base pairs form favourable bonds with bond properties which are intermediate to those of soft and hard acid-base pairs [98-100]. Imidazole is generally considered to be a moderate $\sigma$-donor and a weak $\pi$-acceptor, with $\sigma$-donor and $\pi$-acceptor abilities in between saturated amines such as ammonia $\left(\mathrm{NH}_{3}\right)$ and unsaturated amines such as pyridine [95]. This positions imidazole above oxygen donors and below ammonia and pyridine in the spectrochemical series $[95,106]$. In rare cases, $\pi$-donor abilities from the imidazole-ring $\pi$-orbital have been reported $[107,108]$.

The series of nitrogen donor ligands with increasing basicity follows the order $\mathrm{NH}_{3}>$ imidazole $>$ pyridine, whereas the order of increasing $\pi$-acceptor ability is the reversed [95]. For $\mathrm{Cu}(\mathrm{II})$ and $\mathrm{Zn}$ (II), the bond strength follows the order imidazole $>\mathrm{NH}_{3}>$ pyridine, reflecting a dominating importance of $\sigma$-bonding but also a significant contribution from $\pi$-bonding [95].

Triazoles are softer ligands than the corresponding imidazoles with stronger $\pi$-acceptor interaction and weaker $\sigma$ donor (basicity) interaction [109]. For azoles, the series of increasing $\sigma$-basicity and decreasing $\pi$-acidity follows the order 1,2,4-triazole $>$ pyrazole $>$ thiazole $\gg$ imidazole [110]. Consequently, triazole ligands are better than imidazole in stabilizing $\mathrm{Cu}^{+}$in favour of $\mathrm{Cu}^{2+}$.

\section{Functionalization of Polymers}

For the antifouling coatings containing azole ligands as described in Sections 1.2 and 1.3, it is necessary to develop suitable synthetic routes in order to functionalize polymers with azole ligands. All polymers and low molecular weight imidazole containing substances used in this work are presented in Scheme 1. We have investigated both $\mathrm{N}$ - and Csubstituted azoles. The attachment position of the polymer backbone (the substituent) on the azole ring has important consequences for the coordination chemistry as described in Section 6.1.

3.1. Imidazole Functionalization. A popular technique to functionalize polymers is to graft functional groups onto an active site on the polymer backbone [111-116]. It is often easier to polymerize a smaller monomer with an active site than a large bulky monomer with the functional group already attached. This type of functionalization is sometimes called postpolymerization modification $[115,116]$.

An epoxide route was used in order to functionalize ethyl(hydroxyethyl)cellulose (EHEC) with imidazole groups [49]. In short, the procedure involved 4 steps: protection of 
Bonding modes

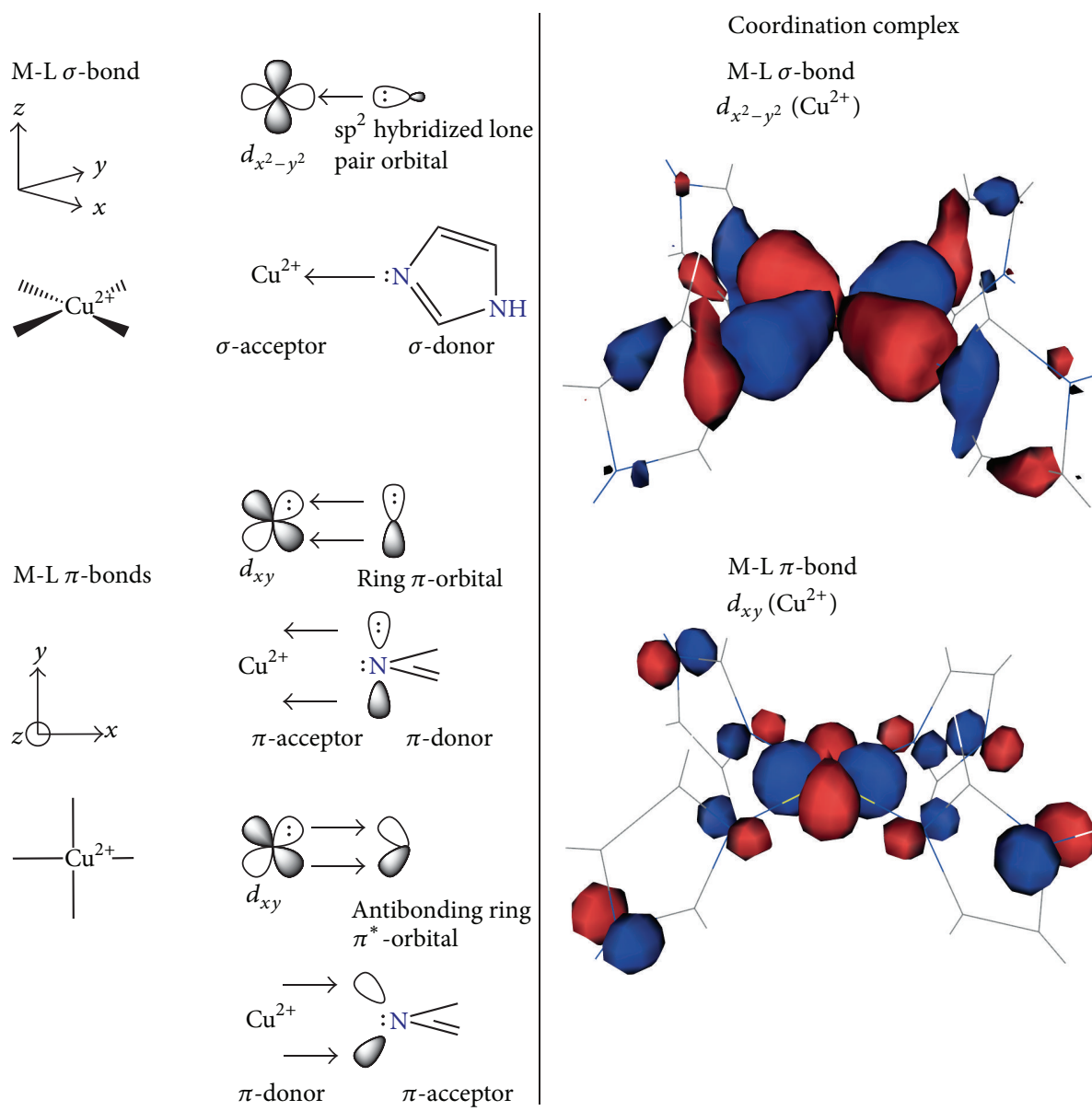

Ligand orbitals

$\sigma$-donor

Orbital of the lone pair on $\mathrm{N}_{3}$

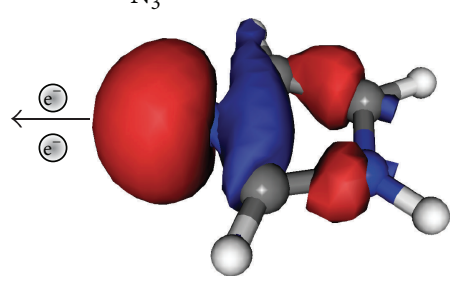

$\pi$-donor

Highest occupied $\pi$-orbital

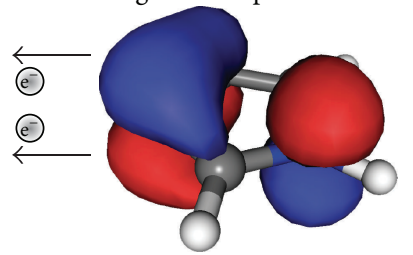

$\pi$-acceptor

Lowest unoccupied $\pi^{*}$-orbital

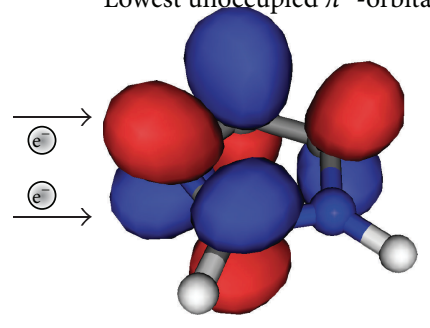

Scheme 5: Coordinate bonding modes (left) and molecular orbitals (right) envisaged for azole-Cu(II) in square planar geometry as obtained from DFT calculations [38]. The bonding principles are generic and applied also for $\mathrm{Zn}(\mathrm{II})$ and $\mathrm{Cu}(\mathrm{I})$ complexes.

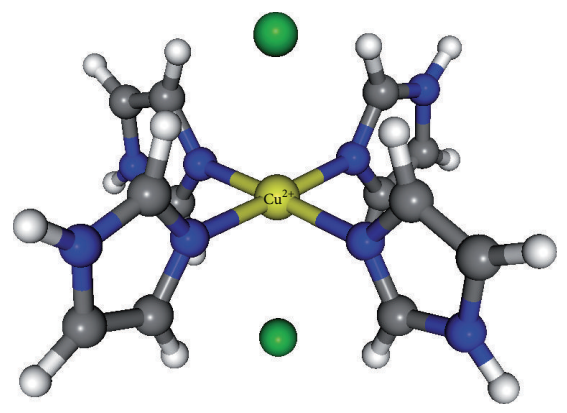

(a)

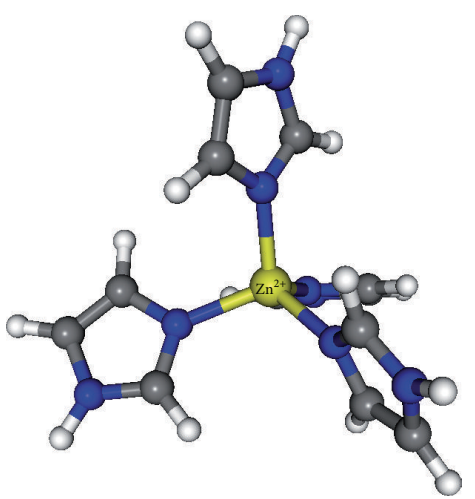

(b)

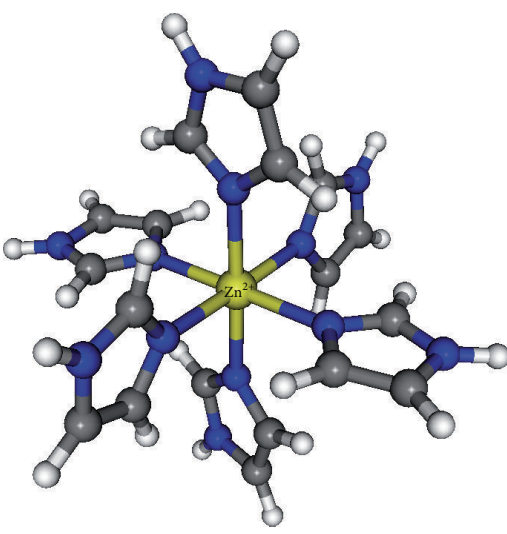

(c)

Scheme 6: Coordination geometries for imidazole-Cu(II) or $-\mathrm{Zn}(\mathrm{II})$ complexes [38]. (a) Square planar $\left[\mathrm{Cu}(\mathrm{Im})_{4}\right]^{2+}$. (b) Tetrahedral $\left[\mathrm{Zn}(\mathrm{Im})_{4}\right]^{2+}$. (c) Octahedral $\left[\mathrm{Zn}(\mathrm{Im})_{6}\right]^{2+}$. 


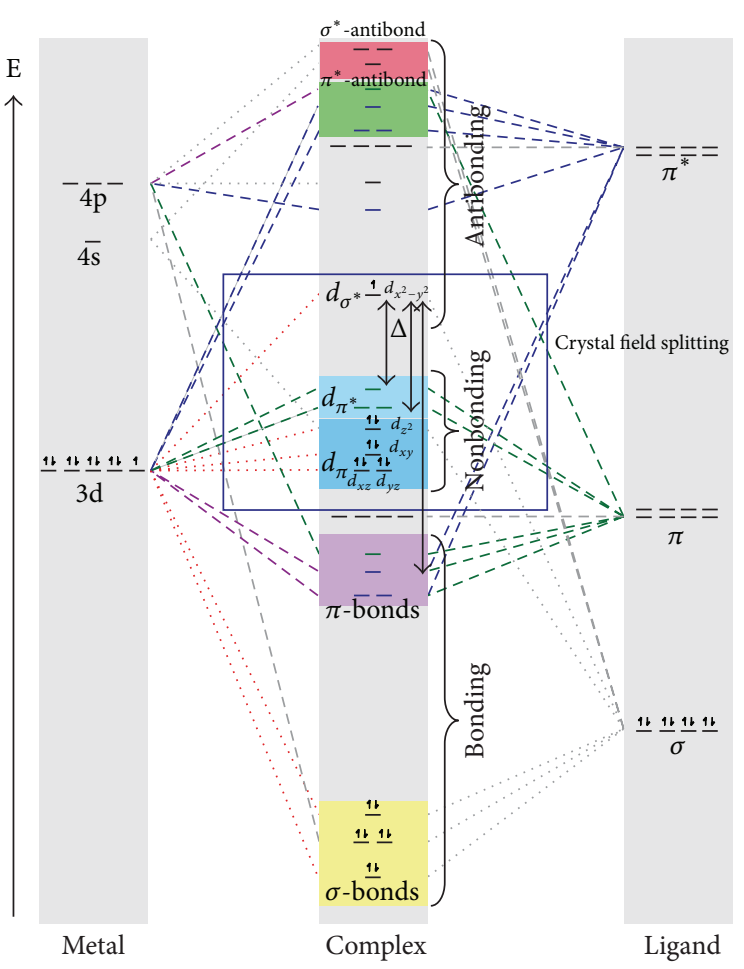

$\mathrm{Cu}(\mathrm{II})$ square planar ligand field

$\sigma$ levels

Bonding $\pi$-interaction with either

ligand electrons ( $\pi$-donor ligand) or

stabilized $d_{\pi}$ electrons ( $\pi$-acceptor ligand)

Destabilized $d_{\pi}$-orbitals

by $\pi$-donor ligand

Nonbonding $d_{\pi}$-orbitals

and $d_{z^{2}}$

$\pi^{*}$ levels

$\sigma^{*}$ levels

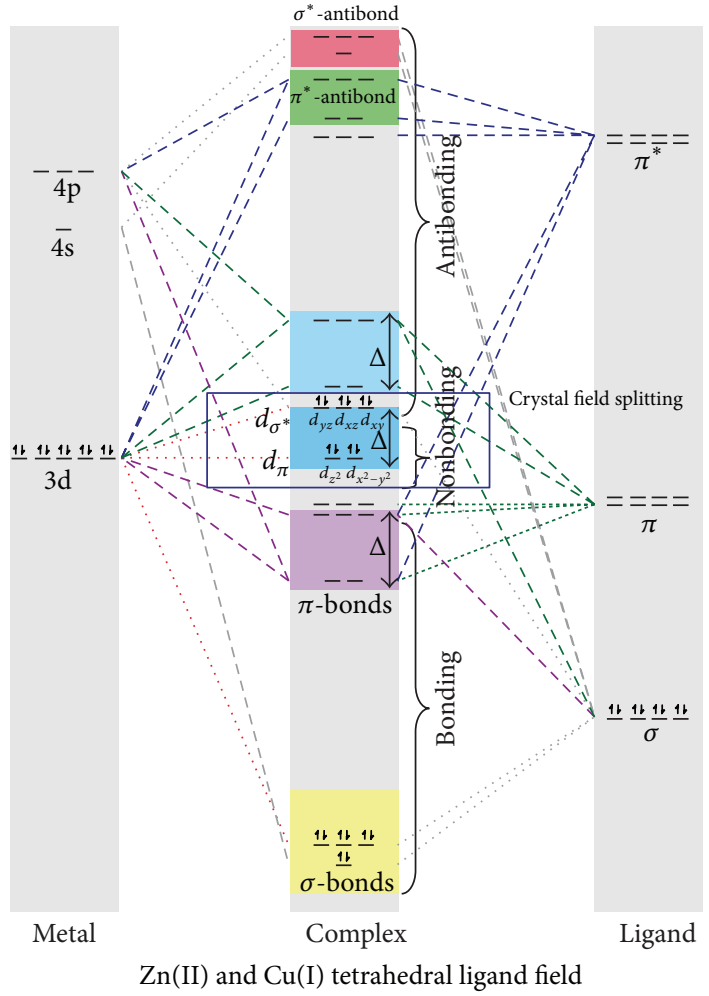

Destabilized $d_{\pi}$ and

$d_{\sigma}$-orbitals by $\pi$-donor ligand

Nonbonding $d_{\pi}$-orbitals

Metal $d$-orbital splitting

$--\pi$-interaction

- - $\quad \pi$-interaction with $\pi$-donor ligand

- - $\quad \pi$-interaction with $\pi$-acceptor ligand

(a)

(b)

Scheme 7: (a) Molecular orbitals and ligand field splitting of $\mathrm{Cu}$ (II) in a square planar complex and of (b) $\mathrm{Zn}$ (II) or $\mathrm{Cu}$ (I) in a tetrahedral complex [96]. (a) With regard to cupric complexes, there is possibility for weakly bound counterions or coordinating solvent molecules in axial position and the geometry is then labelled tetragonal (distorted octahedral symmetry). However, the ligand field splitting will be similar in tetragonal and square planar symmetry if one accounts for the important $4 \mathrm{~s}-3 \mathrm{dz}^{2}$ mixing, which effectively lowers the metal $\mathrm{dz}^{2}$ orbital in both symmetries [97]. (b) The ligand field splitting in tetrahedral complexes is the inverse of an octahedral one but with some mixing of the $\mathrm{d}_{\sigma}$ and p-orbitals. The situation with $\pi$-interaction is, however, more complicated since the $\pi$-interacting ligand orbitals may form both $\sigma$ and $\pi$-bonds, and the effect on the ligand field splitting will be a reflection of both bonding modes [96, 97].

the pyrrole nitrogen, reduction of the aldehyde to epoxide, epoxide opening and attachment to the polymer backbone, and finally removal of the protective group (see Scheme 8). The modified polymer and its interaction with $\mathrm{Cu}^{2+}$ are evaluated in Section 4.2.2.

We have also developed a synthesis procedure to attach the biological amino acid histidine to a polymer backbone as well as to a polymerizable monomer using maleimide chemistry [48]. The synthetic routes comprised both grafting onto by maleimide bond formation on a maleic anhydride polymer (see Scheme 8) and conventional radical polymerization (see Scheme 8). The successful grafting of histidine onto $\mathrm{P}$ (E-altMAh) (poly(ethylene-alt-maleicanhydride)) was confirmed by the formation of the maleimide bond. The DS (degree of 


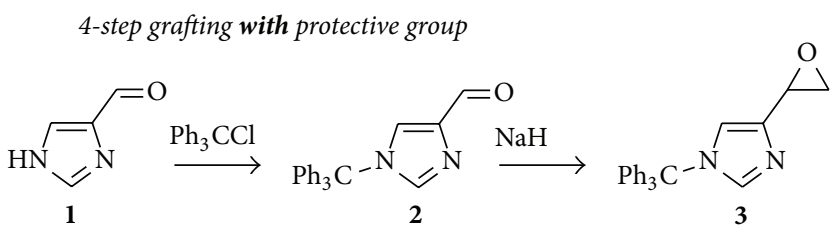<smiles>CCCOCC(O)c1cn(C)cn1</smiles>
4<smiles>CCOCC(O)c1c[nH]cn1</smiles>

Im-EHEC (see Figure 11)

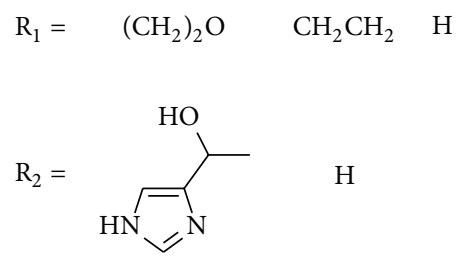

EHEC $=$

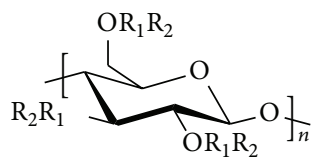

1-step grafting without protective group<smiles>N[C@@H](Cc1c[nH]cn1)C(=O)O</smiles><smiles>COC(=O)[C@H](N)Cc1c[nH]cn1</smiles>

2<smiles>O=C1OC(=O)[123I]1</smiles>

1 or 2<smiles>[R20]C(=O)C(Cc1cnc[nH]1)N(C([R1])=O)C([R1])=O</smiles><smiles>[R][CH-]C=CC</smiles><smiles>CCCC(C)C1C(C)C1C</smiles>

$\mathrm{R}_{2}=\mathrm{H}, \mathrm{CH}_{3}$

HMI, maleoyl histidine

$\mathrm{P}(\mathrm{E}-$ alt-HMI), poly(ethylene-alt-N-histidyl maleimide) $\mathrm{P}(\mathrm{E}$-alt-HMI) methylester (see Figure 11)

Monomers for AIBN initiated radical polymerization<smiles></smiles>

1 (HMI)<smiles>C=Cn1ccnc1</smiles>

3

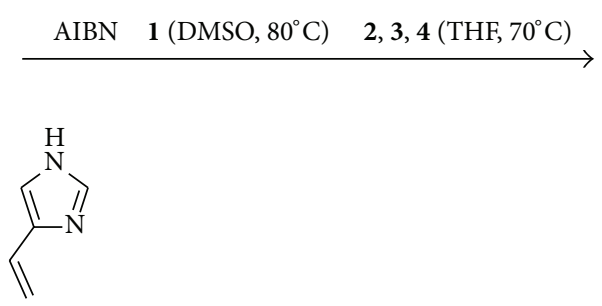

PVM, P(1-VIm), P4VM

PHMI, PMMA (see Figure 11)

SCHEME 8: Imidazole functionalization of polymers and monomers $[48,49]$ and monomers used for AIBN initiated radical polymerization $[39,47,48]$.

substitution) ranging from $80-90 \%$ was estimated from NMR spectra and elemental analysis. In conclusion, imide bond formation between amine and anhydride is an efficient way of grafting histidine onto a polymer backbone [48].

Radical or anionic polymerization of maleimide monomers is an established synthesis procedure, thoroughly investigated [120-128]. Since the maleimide group is strongly electron withdrawing, effectively reducing the electron density at the maleic double bond, it is custom to copolymerize it with for example, styrene or other monomers containing electron donating groups. Such a copolymerization results in rather alternating copolymers [120]. This copolymerization technique is also common for polymerization of maleic anhydride, which is not possible to homopolymerize [120]. However, it is still possible to homopolymerize maleimides, even though the reaction rate is very slow [125]. The reaction rate in this case is additionally decreased since the histidine side group renders the monomer large and bulky [122, 129]. Both routes were successful, but the maleimide route facilitates both grafting onto and radical polymerization. 
Furthermore, the maleimide route is conveniently carried out in one step without the necessity of protective groups [48].

Another way of functionalizing polymers is to copolymerize with the monomer of the polymer with a small fraction a functional comonomer. We have functionalized PMMA with imidazole moieties by simple copolymerization using AIBN as initiator (see Scheme 8). Copolymers of MMA (methylmethacrylate) and 1-VIm (1-vinylimidazole or N-vinylimidazole) (poly(1-VIm-co-MMA, or poly(NVIm-co-MMA) abbreviated PVM) [47] as well as 4-VIm (4-vinylimidazole) (poly(4-VIm-co-MMA) were polymerized using conventional AIBN radical polymerization (see Scheme 8) with the rationale of functionalizing PMMA which is the most commonly used microcapsule shell material [47, 57-59, 63] (see Section 1.1). The polymerization results in statistical copolymers with a higher reactivity ratio for MMA compared with 1-VIm as demonstrated by Wu et al. [130].

\subsection{Triazole Functionalization and Click Chemistry. In con-} formity with the vinylimidazole-based polymer, polymers based on vinyltriazoles (1-vinyl-1,2,4-triazole [131], 1-vinyl1,2,3-triazole [132], and 4-vinyl-1,2,3 triazole [132]) may be prepared by conventional AIBN-initiated radical polymerization [131, 132]. These polymers have found use as heavy metal binding resins for waste water treatments [131] and proton conductors (C-substituted 4-vinyl-1,2,3 triazole) [132].

However, triazole synthesis is most synonymous with the copper catalyzed alkyne-azide huisgen cycloaddition (CuAAC) reaction [117] (see Scheme 9). This reaction is a well-known example of a class of chemical reactions called "click reactions" defined for the first time by Kolb et al. [133]. Click reactions are characterized by high quantitative yields and tolerance towards the use of functional groups. The reactions are also relatively insensitive to the solvent system. Consequently, these characteristics make click reactions a very good tool for polymer synthesis and modifications.

It is obvious that the CuAAC reaction can be used for triazole functionalization of azide or alkyne containing polymers which has been investigated by us [50]. However, the CuAAC reaction can also be used to synthesize triazole-based vinyl monomers. Thibault synthesized vinyl containing triazole monomers $\left(\mathrm{R}_{1}=\right.$ vinyl in Scheme 9$)$ which were polymerized via reversible addition chain-transfer (RAFT) reaction [134]. Using this methodology, a variety of monodisperse polymers carrying different functional group were synthesized [134].

\section{Properties of Coordinated Polymers}

The coordination of polymers carrying ligand sites by metal ions has a profound effect on the polymeric material [135139], which includes properties and functions such as optical, electrical, rheological, molecular self-assembly, and solubility properties [137-141]. The basis for the majority of properties and functions relies on the specificity and strength of coordination for a given set of metal ion and ligand. Therefore, regarding the use of these materials in antifouling coatings (triggered release or $\mathrm{Cu}^{2+}$ sorption/redox reaction), it is important to understand the details of the coordinate interactions on both a microscopic and a macroscopic levels.<smiles>[R]c1cnnn1[R]</smiles><smiles>[R]c1cn([R2])nn1</smiles><smiles>[R]c1cn([R2])nn1</smiles>

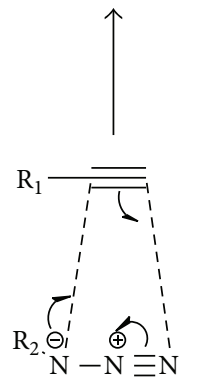
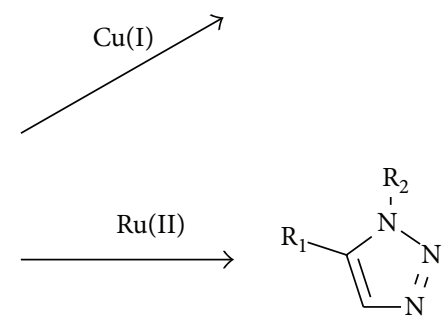

Scheme 9: Dipolar 1,3-cycloaddition of an azide and an alkyne. The regular Huisgen 1,3 dipolar cycloaddition between an azide and an alkyne results in a mixture of 1,4- and 1,5 substituted triazoles [117]. The CuAAC reaction is stereospecific and yields 1,4 substituted triazoles [118]. The reaction can also be catalysed by $\mathrm{Ru}(\mathrm{II})$ which yields 1,5 substituted triazoles [119].

In our group, the coordinate interaction of the materials has been characterized using EPR, vibrational spectroscopy (far-FTIR and mid-FTIR), $a b$ initio, and DFT (Density Functional Theory) calculations. The material properties have been characterized using mainly DSC (differential scanning calorimetry) and vibrational spectroscopy.

4.1. Bond Strength and Selectivity. Regarding the PVM copolymers discussed in Section 3.1, the polymer contains two possible metal-coordinating ligands: the imidazole and the ester groups (see Scheme 1). The carbonyl group is regarded as a hard ligand with the oxygen atom as the ligating group, although with a theoretical possibility of acting as a soft $\pi$-bond donor [100]. However, the metal ions exclusively coordinate the imidazole ligand of the polymer [47]. This is evident since only imidazole bands in FTIR are altered upon coordination (see Figure 1) [39, 47]. Regarding copper complexes, EPR affirms this fact since complexation of PMMA results in no signal (see Figure $2(\mathrm{c})$ ). The EPR results concern only $\mathrm{Cu}^{2+}$ complexes. $\mathrm{Zn}^{2+}$ is diamagnetic and hence EPR silent. Furthermore, the environment appears to be square planar (or tetragonal) due to the resemblance between the EPR spectra of square planar $\left[\mathrm{Cu}(\mathrm{Me}(1)-\mathrm{Im})_{4}\right]^{2+}$ and PVM$4-\mathrm{Cu}^{2+}$. This result is quite spectacular since the enforced coordination symmetry results in a high entropic penalty for the polymer chain. It should be noted that the EPR parameters and spectrum of PVM-4-Cu ${ }^{2+}$ are especially similar to imidazole methylated at position 1 ( $\mathrm{Me}(1)-\mathrm{Im})$ coordinated by $\mathrm{Cu}^{2+}$ (see Figure 2) $[38,47]$.

Publications on polymers containing the $\mathrm{C}_{4}$ substituted 4 -vinylimidazole are rare in comparison with $\mathrm{N}_{1}$ substituted 1 -vinylimidazole, yet interesting due to the unsubstituted pyrrole nitrogen (see Schemes 1 and 8). Note that biological imidazole moieties, such as histidine, are never $\mathrm{N}_{1}$-substituted [38] (see Section 6.1). Sato et al. have studied homopolymers 


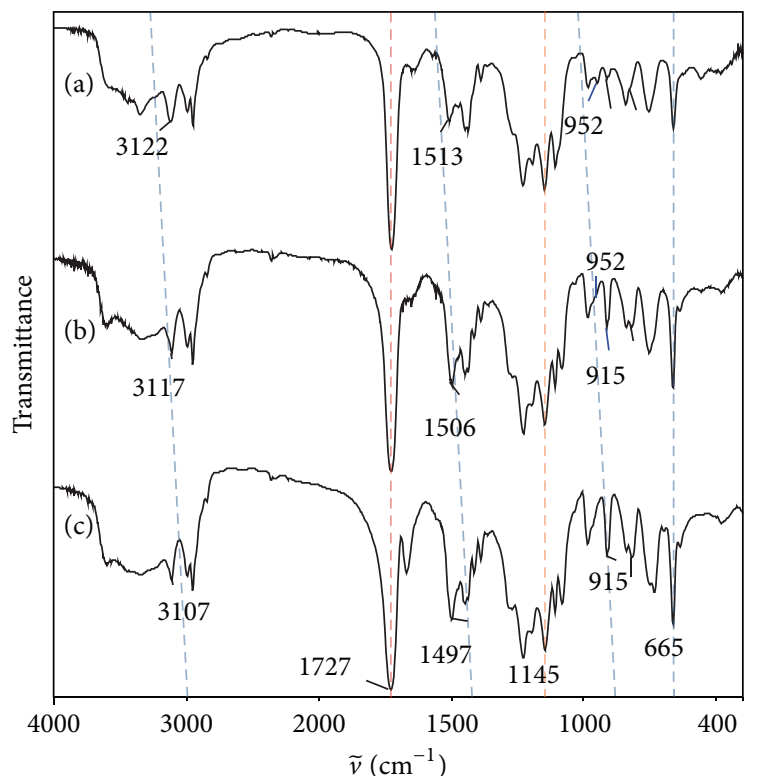

FIgURE 1: FTIR spectra of PVM-44 (c) coordinated by $\mathrm{Cu}^{2+}$ (a) or $\mathrm{Zn}^{2+}$ (b) [47]. As a result of complexation, some FTIR bands of the imidazole (marked blue) are shifted, in particular the in-plane skeletal vibrations of the imidazole ring. However, the carbonyl stretch of the MMA methylester (marked red) remains unaltered.

of poly(4(5)-vinylimidazole) [142-144] which appeared to be coordinated by $\mathrm{Cu}^{2+}$ in a square planar/tetragonal geometry. The copolymers investigated by us, poly(4(5)-VIm-coMMA), appeared to form stronger bonds than the corresponding $\mathrm{P}(1-\mathrm{VIm}-\mathrm{co}$-MMA) polymers as manifested by a complete insolubility of the resulting metal complex. In contrast, the metal complexes of P(1-VIm-co-MMA) were soluble in strongly coordinating solvents, for example, DMSO, $\mathrm{MeCN}$, or DMF [47].

4.2. Coordinate Crosslinks. The coordinate bonds between the imidazole ligand and the metal ions generate crosslinks between the polymer chains [47]. The crosslinks cause the glass transition temperature, $T_{g}$, to increase since the chain segments in proximity of a crosslink are stiffened due to the reduced rotational freedom (see Figure 3) $[47,145]$. The stiffness depends on the strength of the crosslink. Hence, the increase of $T_{g}$ will depend on both the number of effective crosslinks as well as the strength of the crosslinking bond [47, $135,136,146]$. Regarding the polymers, the increase of $T_{g}$ is more pronounced for PVM-44 than PVM-4 due to the larger number of possible crosslinks. However, when the effect of the particular metal ion is inspected, it is observed that $\mathrm{Cu}^{2+}$ raises $T_{g}$ more than $\mathrm{Zn}^{2+}$ for PVM- 4 while the opposite holds for PVM-44. This may appear contradictory but is explained by coordination bond strength and coordination number. The bond strength between imidazole and $\mathrm{Cu}^{2+}$ which is stronger than the bond strength between imidazole and $\mathrm{Zn}^{2+}$ which is most important for PVM-4 with a low number of imidazole ligands. However, the total number of possible

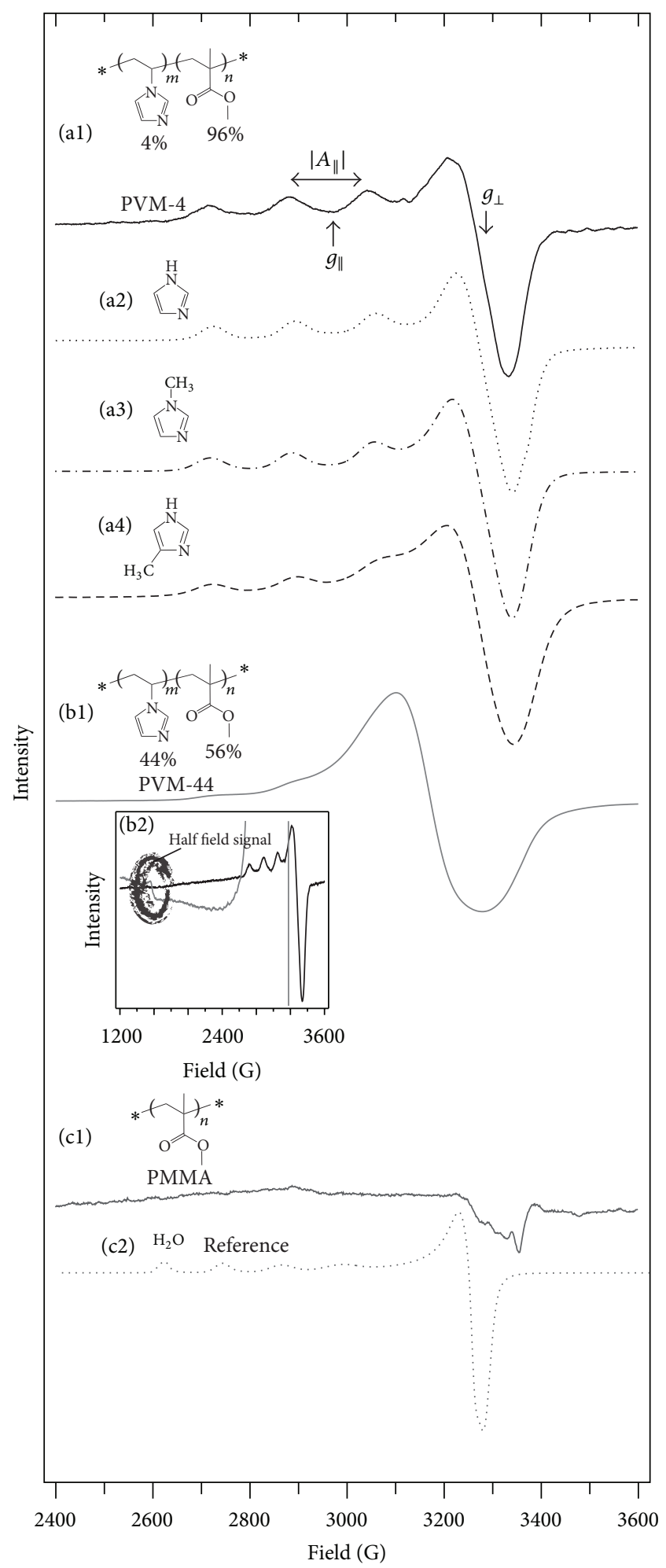

Figure 2: $\mathrm{Cu}^{2+}$ EPR spectra in MeCN of (a1) PVM-4, (a2) Im, (a3) Me(1)-Im, (a4) Me(4)-Im, (b1) PVM-44, (b2) PVM-44 half field signal, (c1) PMMA, and (c2) $\mathrm{H}_{2} \mathrm{O}[38,47]$. The paramagnetic centers, that is, the $\mathrm{Cu}(\mathrm{II})$ ions, of PVM-44 are closer together compared to PVM-4 which is reasonable due to the larger fraction of imidazole ligands per polymer chain. To be more precise, the coordination complexes are separated by less than $20 \AA$ (see Figure 2(b2)) which is indicated by the EPR half field signal (see Figure 2(b2)). 


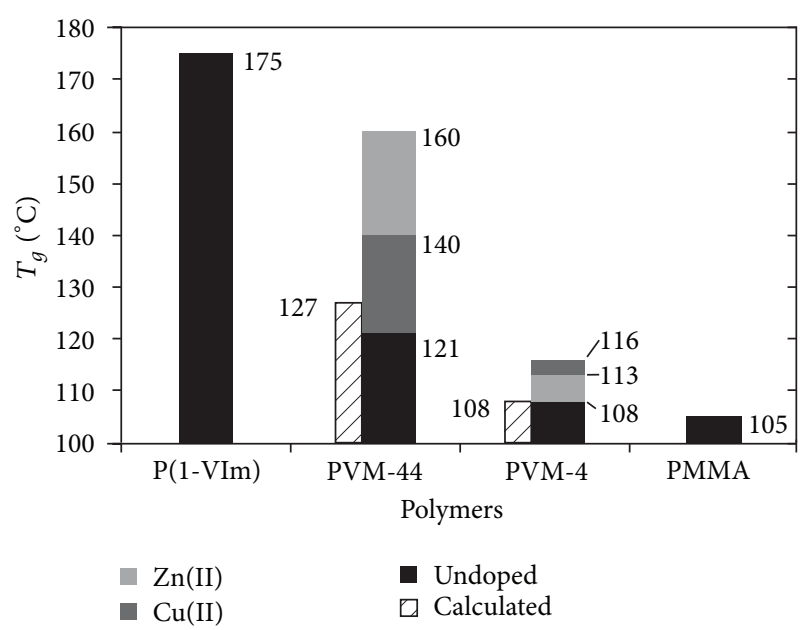

FIGURE 3: Glass transition of polymers and polymer complexes [47].

crosslinks may be higher for $\mathrm{Zn}^{2+}$ complexes since this metal allows for octahedral geometry (see Section 2.3), whereas $\mathrm{Cu}^{2+}$ is restricted to square planar geometry. This explains why PVM-44 with a high number of imidazole ligands coordinated to $\mathrm{Zn}^{2+}$ acquires a higher $T_{g}$ than PVM- 44 coordinated to $\mathrm{Cu}^{2+}$ despite a weaker coordinate bond.

4.2.1. Hygroscopicity and Metal Coordination. The hygroscopicity of a PVM polymer containing a metal ion salt is highly dependent on the fraction of imidazole containing monomers. In addition, the water molecules can crosslink two imidazole groups of a PVM polymer in a similar manner as the metal cation. The hydrogen-bond interaction is too weak to alter the thermal properties of the polymer, yet, the change of the polarization of the water molecules is evident by the blue shift of the $\delta(\mathrm{HOH})$ water bending vibration (see Figure 4). However, when metal ions are introduced, this population of bridged water molecules disappears and is replaced by bridging metal ions (see Figure 4) [39, 47]. For PVM-4, with a low fraction of imidazole ligands, the introduction of metal ions results in a significant increase of solitary water as indicated by the area of the $v(\mathrm{OH})$ water stretching vibrations [39]. However, for PVM-44 with a high fraction of imidazole ligands, the metal ion coordination results in a decrease of the amount of sorbed water [39]. Note that this polymer is already rather polar due to the high fraction of N-VIm monomers. Consequently, the triggered release effect discussed in Section 1.2 is more applicable for hydrophobic polymers which are functionalized with crosslinking metal ions.

4.2.2. Coordination-Mediated Multilayer Assembly. The strong coordinate cross-links discussed previously can be used to assemble polymer multilayers. Polymer multilayers are most synonymous with the polyelectrolyte layer-by-layer technique which has received a lot of attention during the last decade [64]. However, coordination chemistry is a feasible tool to assemble multilayers with anisotropic properties as provided by the restricted coordination geometry of a given metal ion. Hedin et al. studied the bilayer formation of the imidazole functionalized biopolymer Im-EHEC (see Scheme 1) using QCM-D [49]. Although Im-EHEC was functionalized with only $1 \%$ imidazole moieties per monomer unit, the introduction of copper resulted in a slight crosslinking of the adsorbed polymer layer, and the subsequent addition of Im-EHEC solution gave an additional adsorbed monolayer of Im-EHEC (see Figure 5).

\section{Antifoulant Immobilization and Controlled Release}

In the following subsections, ways to immobilize and control the release of antifouling agents using coordinate interactions, with a special focus on medetomidine, will be presented. The immobilization of medetomidine has been evaluated using HPLC, NMR, and vibrational spectroscopy as well as monitored in situ in model systems using QCM-D and SPR. The controlled release has been monitored from real coatings using liquid scintillation spectrometry $\left({ }^{14} \mathrm{C}_{-}\right.$probed release substances) as well as from model surfaces using the surface sensitive techniques QCM-D and SPR.

5.1. Polymer Coordination. Triazole derivatives represent a wide class of antimicrobial substances (see Scheme 1) [1927] as mentioned in the Introduction. Their use in antifouling coatings has been claimed in a number of patents [147150]. As an example, Tanaka and coworkers immobilized antifoulants based on triazole, thiadiazole, and benzotriazole in resins containing a high fraction of carboxylate groups [147].

In a similar manner, Shtykova et al. studied the immobilization of the imidazole containing medetomidine (see Scheme 1) on an alkyd resin using NMR diffusometry [44]. It was found that the self-diffusion coefficient of medetomidine was decreased by more than one order of magnitude due to immobilization of medetomidine on the alkyd resin. It was proposed that the mechanism of immobilization was hydrogen bonding between the protonated imidazolium ion of medetomidine and deprotonated carboxylate groups of the alkyd resin [44].

This concept was further developed by Handa et al. to encompass polymers with very strong Lewis acid sites. Medetomidine was immobilized and released from the sulphonated polymer SPSEBS (see Scheme 1, the nonsulphonated polymer PSEBS was used as a reference) as monitored in situ using QCM-D [41]. In the solvent xylene, large amounts of medetomidine were adsorbed almost irreversibly, which was ascribed to a coulombic charge-transfer reaction in the hydrophobic solvent. The interaction was much weaker in artificial seawater with less adsorbed medetomidine and a pronounced release upon rinsing [41]. This system could consequently be used as a triggered release system (see Scheme 2) as discussed in Sections 1.1 and 1.2. 


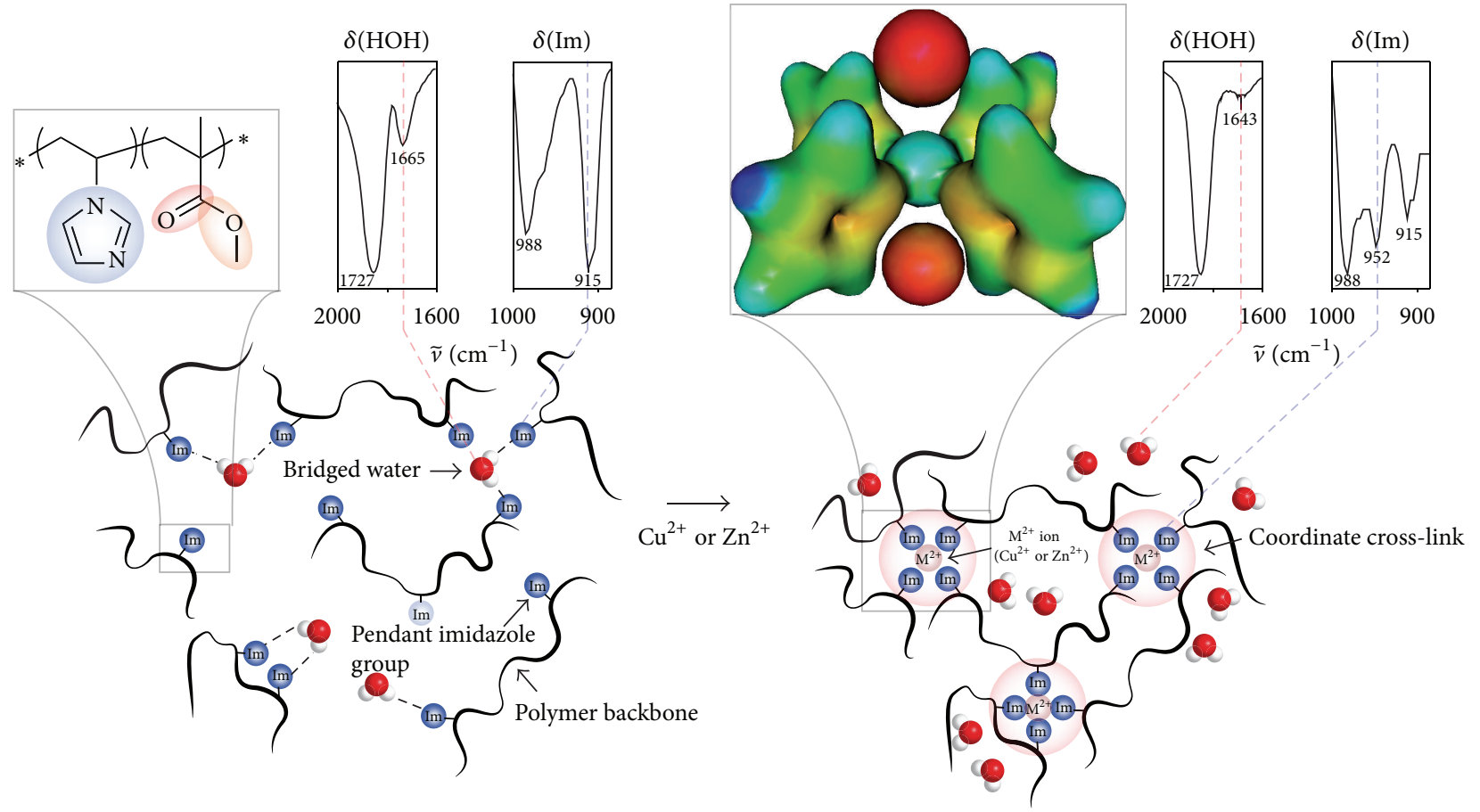

FIGURE 4: Schematic drawing of Im- $\mathrm{H}_{2} \mathrm{O}$-Im bridged water and subsequent replacement by $\mathrm{Cu}^{2+}$ or $\mathrm{Zn}^{2+}$, including the most important markers for $\mathrm{H}_{2} \mathrm{O}$ and $\mathrm{Im}$, respectively, as well as the electrostatic potential energy surface of the $\left[\mathrm{Cu}(\operatorname{Im})_{4} \mathrm{X}_{2}\right]$ complex as obtained from $a b$ initio calculations [39].

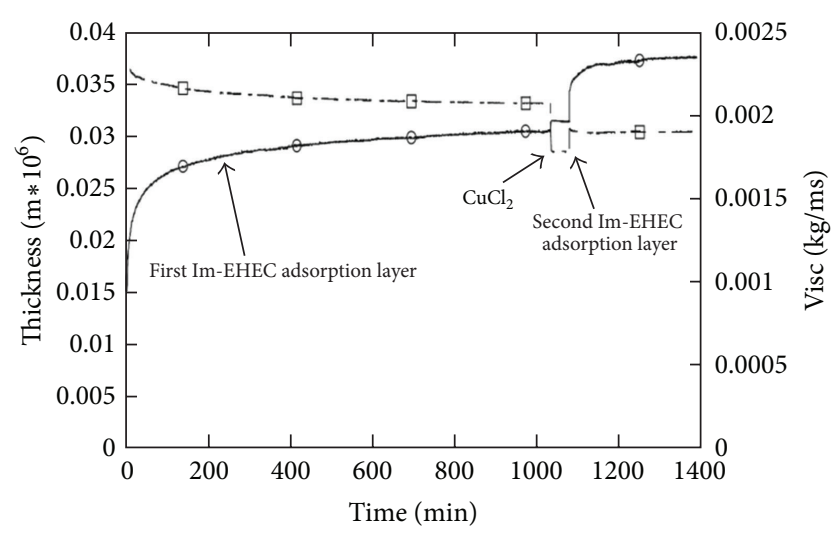

FIGURE 5: Bilayer formation of Im-EHEC (see Scheme 1) with $\mathrm{CuCl}_{2}$ (measured using QCM-D and modeled using a Voight-based viscoelastic model). The second layer is thin and corresponds to a monolayer. Reprinted from [49].

5.2. Metal Ion and Metal Oxide Nanoparticle Coordination. The hydrogen bonds mentioned in the previous section are relatively strong interactions; yet, the strength of coordinate metal-ligand bonds discussed in Section 2 is significantly higher. Therefore, the Nydén group explored the feasibility of using transition metal coordination for medetomidine immobilization. Fant et al. investigated the adsorption and controlled release of medetomidine from PVM polymers (see Scheme 1, PVM-44) coordinated by $\mathrm{Cu}^{2+}$ or $\mathrm{Zn}^{2+}$ using
QCM-D [40]. $\mathrm{Cu}^{2+}$ was adsorbed in much higher amounts than $\mathrm{Zn}^{2+}$ by the PVM polymer which is in line with the stability constants. Moreover, the metal ion adsorption resulted in a pronounced swelling of the PVM polymer by water which corroborates its feasibility to be used as a material for triggered release applications as discussed in Sections 1.2 and 4.2.1. The subsequent addition of medetomidine resulted in significant adsorption for both PVM coordinated by $\mathrm{Cu}^{2+}$ and $\mathrm{Zn}^{2+}$ (see Figure 6). Note that the resulting complex contains imidazole ligands from both the PVM polymer and medetomidine. However, the interaction of medetomidine with $\mathrm{Zn}^{2+}$ was more reversible than with $\mathrm{Cu}^{2+}$ and resulted in a much faster release (see Figure 6). Thus, the release profile may be tailored by coordinating the PVM polymer with mixtures of $\mathrm{Zn}^{2+}$ and $\mathrm{Cu}^{2+}$ [40].

In addition to polymers coordinated by metal ions, metal oxide nanoparticles are feasible vehicles for antifoulant immobilization using coordination chemistry [45, 46]. Shtykova and coworkers studied the immobilization of some common booster biocides including medetomidine and Seanine (see Scheme 1) on different types of metal oxide nanoparticles (see Figure 7). It was apparent that the booster biocides containing ligand moieties (medetomidine, irgarol, diuron, and Seanine) gave the strongest adsorption. Note that the isothiazolinone Seanine (see Scheme 1) has the possibility to bind via hard interaction (carbonyl oxygen) or via soft interaction (sulphur free electron pair). Regarding the nitrogen which is of pyrrole type, interaction at this position is only possible at very high $\mathrm{pH}$ for isothiazolinones which 


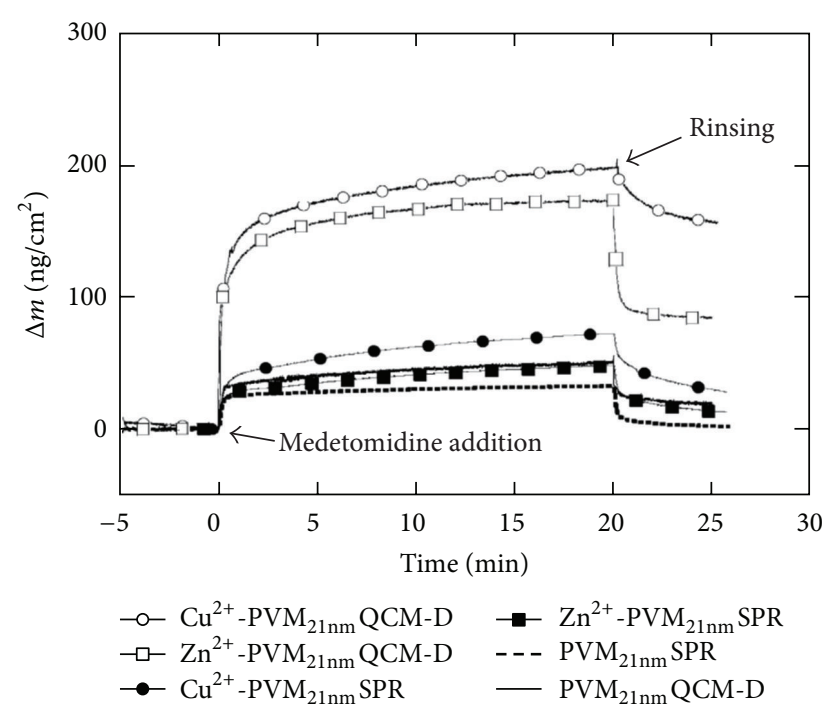

FIGURE 6: Medetomidine absorption (measured using QCM-D and SPR) to a $\mathrm{Cu}^{2+}$ doped, $\mathrm{Zn}^{2+}$ doped, and metal free $21 \mathrm{~nm}$ thick PVM film. It is apparent that metal coordination significantly enhances medetomidine adsorption and that the coordination to $\mathrm{Cu}^{2+}$ is stronger and less reversible. Reprinted from [40]. The combination of QCM-D and SPR measurements can be used to estimate the amount of sorbed solvent in an adsorbed film. The acoustic QCM$\mathrm{D}$ technique probes the entire adsorbed viscoelastic layer, including bound solvent. In contrast, the SPR method measures changes in refractive index at the surface and consequently takes only the mass of the adsorbent into account. The difference in adsorbed mass from QCM-D and SPR measurements can therefore be related to the amount of solvent.

are unsubstituted at position 2. However, the affinity of medetomidine for the metal oxide particles was substantially higher than that of any other biocide. This indicates that the imidazole group of medetomidine is key for its successful immobilization (see Figure 7(a)). The order of increasing interaction strength with the imidazole ligand was slightly different for the metal oxides compared with the corresponding metal ions (see Figure 7(b), and $\mathrm{ZnO}$ displays a stronger interaction with medetomidine than $\mathrm{CuO}$ ) [42]. This is reasonable since the metal centers in the oxides are much more electron-rich compared to the free metal ions. The immobilization of medetomidine on $\mathrm{ZnO}$ nanoparticles (which are common pigments in antifouling marine paints) resulted in a significant decrease in the release rate from a varnish coating as compared with medetomidine molecularly dispersed in the same coating (see Figure 7(c)) [42].

\section{Effect of Ligand Substituent Position and Ligand Chemistry}

The coordinate interaction as described in Section 2 is not only dependent on the type of ligand used but also on the substituents attached at the azole ring. This has been investigated by us in detail using vibrational spectroscopy, EPR, $a b$ initio, and DFT calculations and is presented in Section 6.1.
In Section 6.2, these results are discussed with respect to $\mathrm{Cu}^{2+} / \mathrm{Cu}^{+}$stabilization as presented in Section 1.3.

6.1. "Natural" versus Synthetic Ligands. When inspecting the polymers discussed in Section 3 (see Scheme 1), it is observed that the imidazole ligand is attached to the polymer backbone at either position 1 or 4 , and this holds for in principle any arbitrary imidazole-containing polymer. Moreover, regarding imidazole from biological sources, such as histidine, the imidazole ring is always substituted at position 4 . This is in contrast to synthetic imidazole-containing polymers where the imidazole ring is usually attached to the backbone at position 1, that is, via the pyrrole nitrogen. Subsequently, it may be speculated why nature has chosen this particular position for substituent attachment. To investigate this, the methylated imidazole model compounds $\mathrm{Me}(1)$-Im and $\mathrm{Me}(4)$-Im (see Schemes 1 and 10) were analysed with respect to similarities and differences in coordination strength, coordination geometry, covalency, and so forth [38].

Both compounds display profound covalence in the $\sigma$ bond ( $\alpha^{2}=71 \%$ according to DFT calculations) which is also evident by the hyperfine splitting in the EPR spectrum (see Figure 8) [38]. An even better indication of the high degree of covalence is the $\pi$-interaction coefficient (EPR; $\beta^{2} \approx$ $[0.65,0.69]$, ab initio; $\left.\beta^{2} \approx[0.51,0.60]\right)[38,151]$. Small differences as an effect of position regarding the coordinate interaction are evident since the $\mathrm{Me}-\mathrm{C}_{4}$ bond is slightly more polarizable than the $\mathrm{Me}-\mathrm{N}_{1}$ bond. As a consequence, $\mathrm{Me}(4)$ Im is a stronger base than both $\mathrm{Me}(1)$-Im and Im since the methyl substituent is an electron-donating group (see Scheme 10) [38]. However, the stability constant is lower for the corresponding $\mathrm{Me}(4)$-Im complex compared to $\mathrm{Me}(1)$ $\operatorname{Im}$ and $\operatorname{Im}[38,152]$ which suggest a significant $\pi$-acceptor interaction in addition to the $\sigma$-donor interaction in the coordinate complex [38] as discussed in Section 2. However, much larger effects were obtained by changing the type of substituent as was apparent from $a b$ initio calculation. By systematically changing the position of the substituent as well as the substituting group, it was observed that $\Delta E$ (the energy of complexation) and $v_{a}(\mathrm{M}-\mathrm{L})$ (metal-ligand asymmetric stretch vibration) were more affected by the chemistry of the group than its actual position.

The coordination geometries for $\mathrm{Me}(1)$ - $\mathrm{Im}$ and $\mathrm{Me}(4)$-Im are more or less identical. For instance, the steric hindrance of the methyl group upon coordination is the same for both methylated imidazoles (see Schemes 1 and 10 and Figure 9) since $\mathrm{Me}(4)-\operatorname{Im}$ actually coordinates as $\operatorname{Me}(5)-\operatorname{Im}[38,154]$ due to tautomerism and steric restrictions. As a consequence, the coordination geometries for the methylated imidazole ligands are very similar, both for $\mathrm{Cu}^{2+}$ and $\mathrm{Zn}^{2+}$ complexes, in contrast to unsubstituted imidazole (see Figure 9). However, an important difference between $\mathrm{Me}(1)$ - and $\mathrm{Me}(4)-\mathrm{Im}$ is the reduced "degrees of freedom" for Me(1)-Im. Me(4)-Im, equivalent to Im or triazoles, contains two potential sites for coordination or protonation. Consequently, $\mathrm{Me}(4)-\mathrm{Im}$ and Im may, as a function of ligand metal ratio and $\mathrm{pH}$, form coordination polymers which is restricted to Me(1)-Im [38]. 


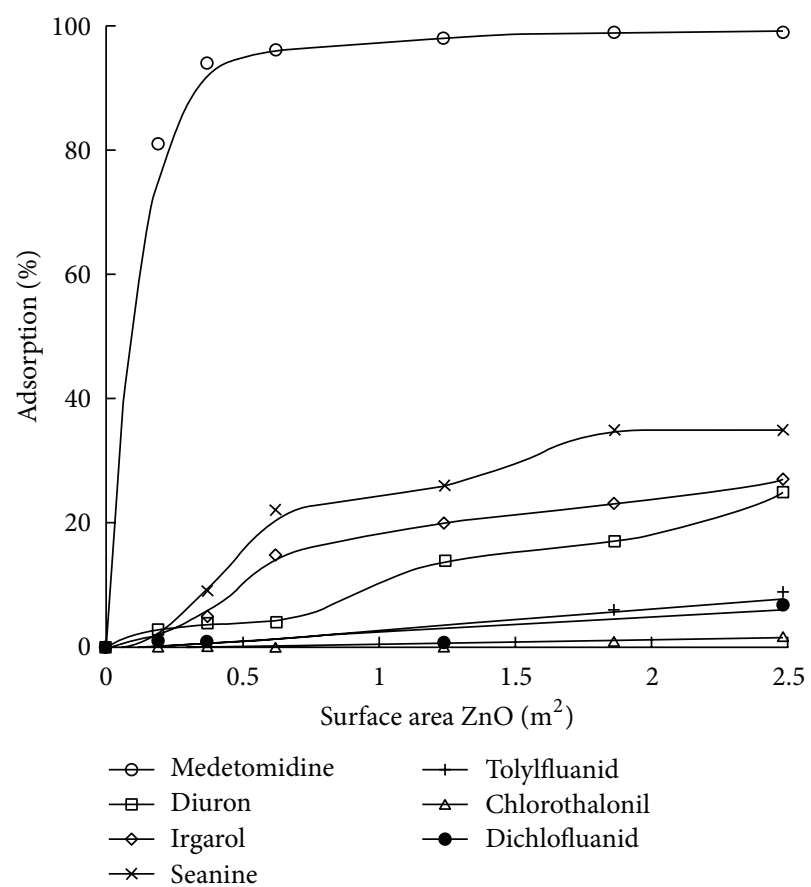

(a)

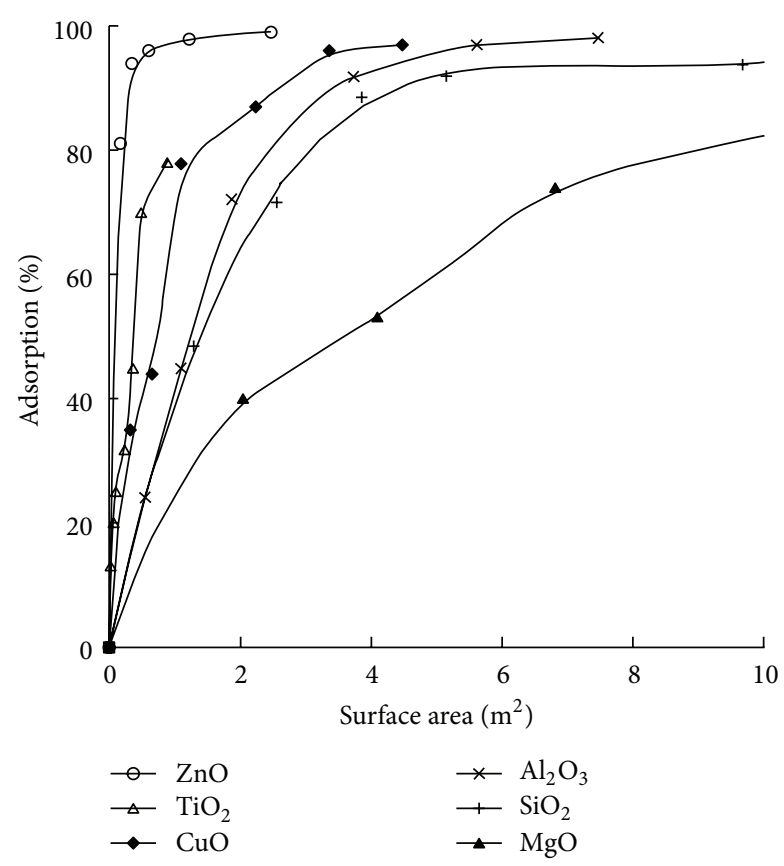

(b)

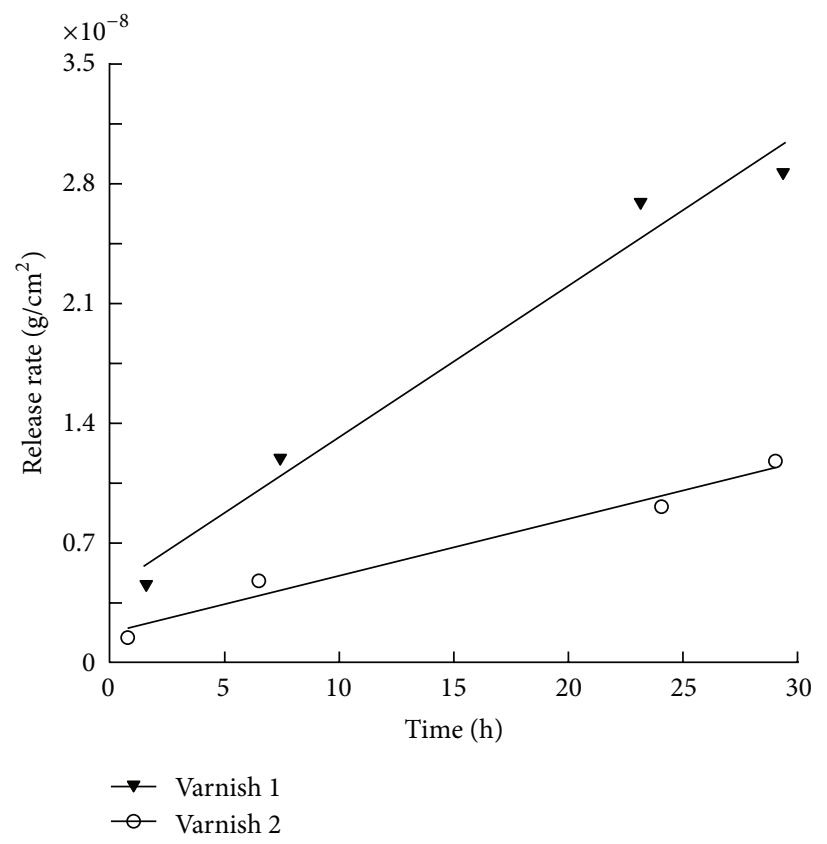

(c)

FIGURE 7: (a) Immobilization efficiency of various booster biocides including medetomidine (see Scheme 1) on $\mathrm{ZnO}$ nanoparticles as a function of total particle surface area. (a) Immobilization efficiency of medetomidine on various metaloxide nanoparticles as a function of total particle surface area. (c) Effect on release of free (varnish 1, $\mathbf{\nabla}$ ) and $\mathrm{ZnO}$ immobilized (varnish 2, o) medetomidine from coatings. Reprinted from [42].

If the polymeric imidazole ligands used in this work are compared, that is, 1-VIm and histidine, the position of the substituent in the imidazole ring is not the most important factor (see Scheme 11). The chemical nature of the substituent, more precisely its electron withdrawing or electron donating abilities, is more important with respect to the coordinate interaction. However, the position of the ring substituent is important when it comes to bidentate coordination, the possibility to conduct protons between adjacent imidazole ligands and ring polarization due to coordinating nucleophiles [38]. 


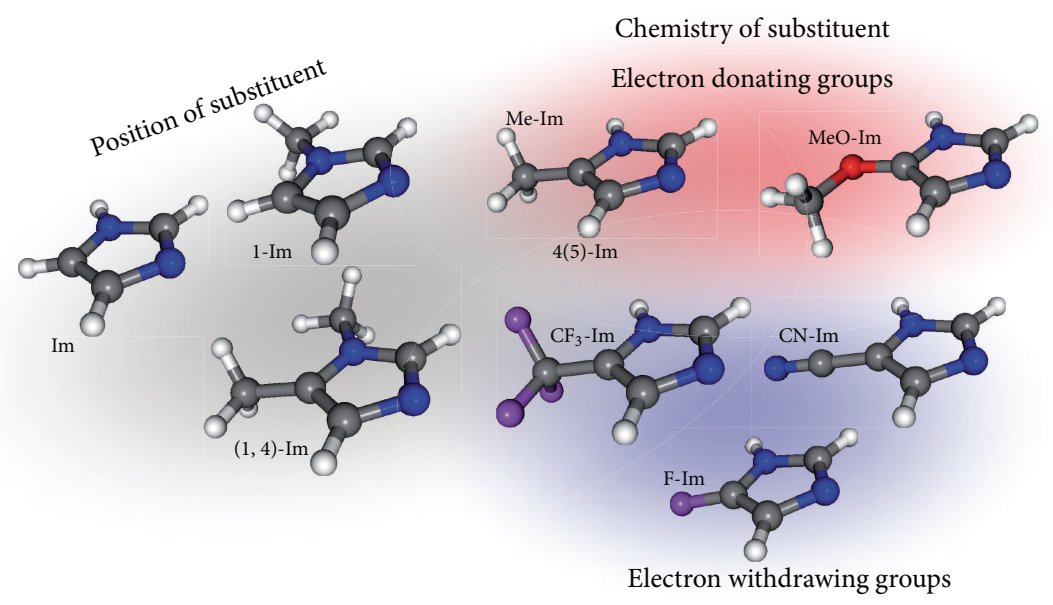

Scheme 10: Imidazole derivatives with various substituents at different ring positions. The molecules have been geometry-optimized using DFT [38].

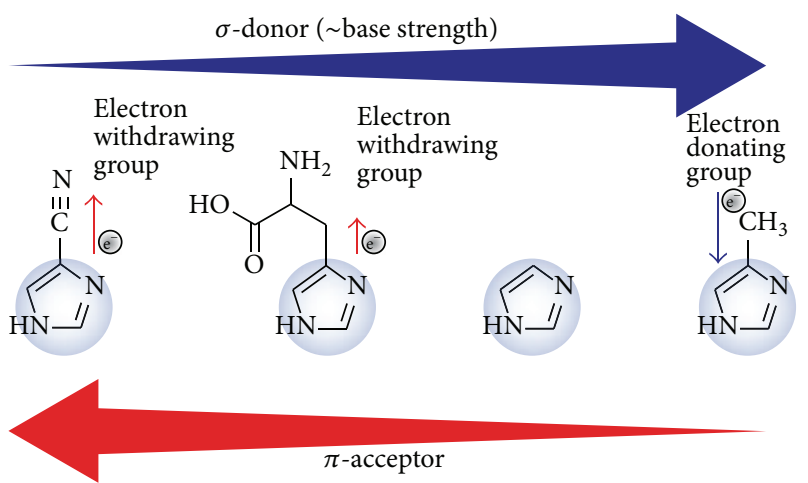

Scheme 11: The effect of the substituent with respect to electron donating/accepting capacity on the coordinate interaction.

6.2. $\mathrm{Cu}^{2+} / \mathrm{Cu}^{1+}$ Stabilization. As mentioned in the introduction, $\mathrm{Cu}^{+}$is highly unstable in water and disproportionates to $\mathrm{Cu}^{2+}$ and $\mathrm{Cu}^{0}$. This is a consequence of the hydrate complex where water, which is a hard base (see Section 2.1), strongly stabilizes $\mathrm{Cu}^{2+}$ (border line acid) over $\mathrm{Cu}^{+}$(soft acid). However, it is possible to alter the redox potential in favor of $\mathrm{Cu}^{+}$ by changing the ligand environment $[100,158]$. In Figure 10, $4 \mathrm{mM} \mathrm{CuCl}_{2}$ has been dissolved in water/glycerol (hard ligands) or acetonitrile (MeCN, soft ligand) [38]. The area of the EPR signal is proportional to the concentration of $\mathrm{Cu}(\mathrm{II})$ ions. The $\mathrm{MeCN}$ system displays a smaller area compared to the water/glycerol system which indicates reduction of $\mathrm{Cu}$ (II) to the EPR silent $\mathrm{Cu}(\mathrm{I})$. It is well known that nitriles strongly stabilize $\mathrm{Cu}^{+}$in favour of $\mathrm{Cu}^{2+}[38,47,76,159-161]$.

However, soft ligands such as nitriles prevent the catalytic ability of $\mathrm{Cu}^{2+} / \mathrm{Cu}^{+}$by stabilizing the $\mathrm{Cu}(\mathrm{I})$ oxidation state too well [76]. In order to find a proper ligand environment, scientists are once again finding inspiration in biological systems, in particular copper containing enzymes [76, 79]. Regarding the efficient catalytic activity and the electron transfer capability found in type 1 blue copper proteins, the ligand set of the copper complex contains both $\mathrm{Cu}^{2+}$ and $\mathrm{Cu}^{+}$stabilizing ligands (histidine and cysteine/methionine resp.) $[79,162]$. In addition, the coordination geometry is forced into a distorted tetrahedral symmetry which is an intermediate geometry between square planar/tetragonal $\left(\mathrm{Cu}^{2+}\right.$ coordination) and tetrahedral $\left(\mathrm{Cu}^{+}\right.$coordination, see Scheme 6) [79]. This has been suggested to facilitate the ease of electron transfer and oxidation/reduction of the copper ion $[79,162]$.

We are currently investigating triazole-based ligands for $\mathrm{Cu}^{+}$stabilization [50] as described in Section 1.3 with respect to antifouling properties. The polymers are synthesized by a grafting onto approach as described for imidazoles [48] in Section 3.1 using the CuAAC click reaction (see Section 3.2). The triazole ligand have, in accordance with imidazole, a very high affinity for $\mathrm{Cu}^{2+}$. Yet, triazole ligands may also stabilize $\mathrm{Cu}^{+}$. Moreover, the coordination geometry can be tuned by the proper spatial distribution of ligands of different chemical nature. By tailoring the ligand environment and the subsequent coordination geometry in triazole containing polymers, our intention is to prepare antifouling hydrophilic polymers [163], inspired by copper enzymes, which may absorb $\mathrm{Cu}^{2+}$ from the sea as well as facilitate the $\mathrm{Cu}^{2+} \rightarrow \mathrm{Cu}^{+}$ reduction.

\section{Conclusion and Outlook}

Azole coordination chemistry shows great potential with respect to antifouling coatings for a number of reasons. Many antifouling agents contain azole moieties. The imidazole containing biocide medetomidine is promising antifouling agent with respect to protection against fouling of barnacles. The fact that the azole moiety is a ligand can be used to immobilize these biocides on macromolecules or nanoparticle and thus control their release (both sustained and triggered release are possible). Moreover, the polymeric materials used for the purpose of controlling the release of antifouling agents can be given new properties via transition 


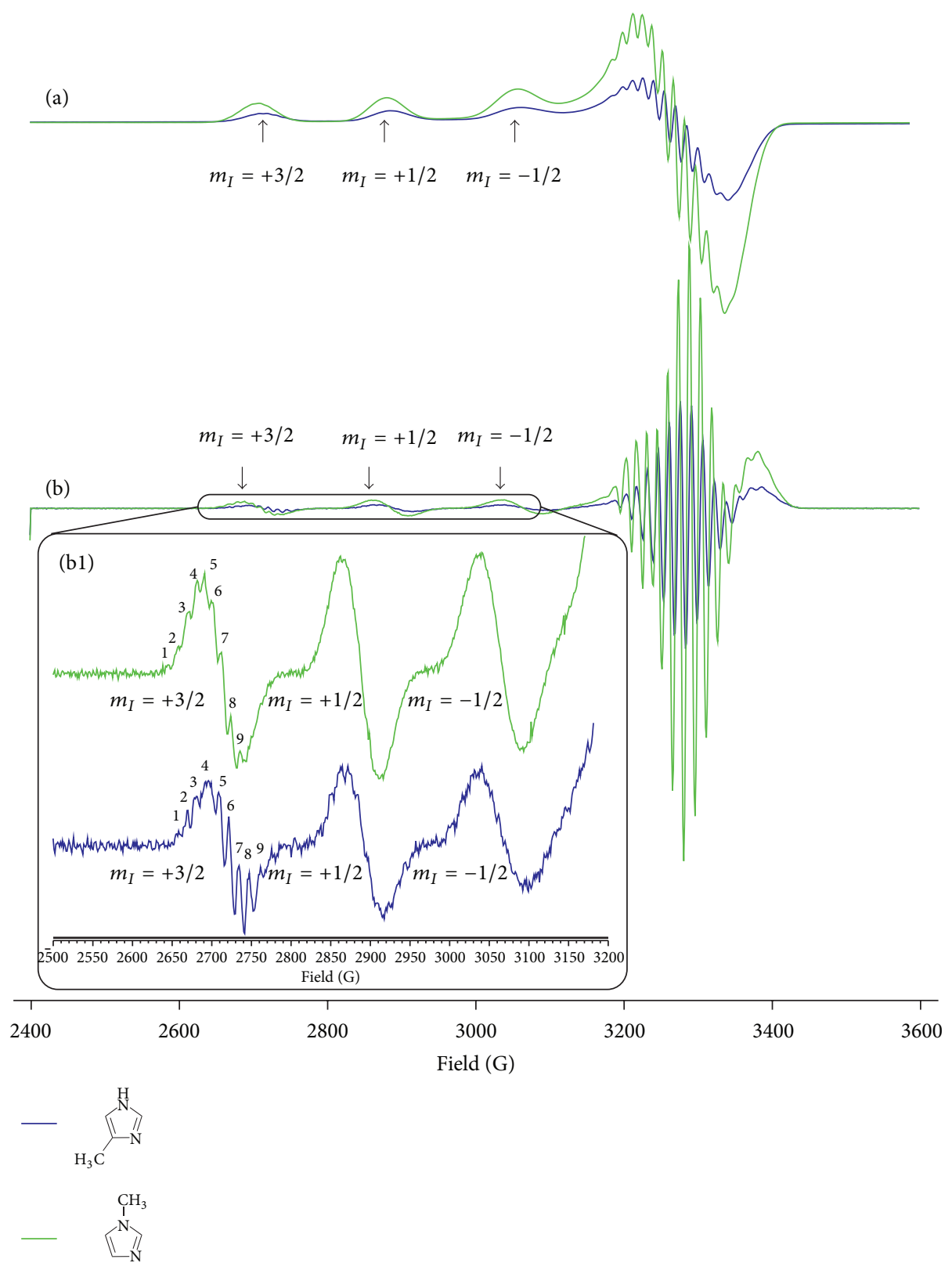

FIGURE 8: Me-Im in water/glycerol. (a) EPR signal of Me(1)-Im (green) and Me(4)-Im (blue). (b) Derivative of the EPR signal with inset (b1) displaying the fine structure at $m_{1}=+3 / 2$ [38]. The fine structure indicates four equivalent ligands. However, some signals appear to be doublets which may be explained by the $\mathrm{Cu}^{2+}$ isotope mixture $[79,153]$.

metal coordination of pendant azole ligands in the polymer. However, the most promising antifouling approach lies in the very strong affinity of azoles for $\mathrm{Cu}^{2+}$ which is a potent antifouling biocide. An antifouling coating containing azole ligands can subsequently absorb large amounts of naturally abundant copper and obtain antifouling protection without any net release of biocide. Moreover, the $\mathrm{Cu}^{2+} \rightarrow \mathrm{Cu}^{+}$redox potential may be altered towards reduction to $\mathrm{Cu}^{+}$, which is the most bioactive oxidation state. This can be achieved by tailoring the ligand chemistry where triazole ligands are promising for these purposes. We believe that the potential of this bioinspired approach has not been fully explored. A lot of inspiration can be found in nature, in particular copper enzymes. These enzymes are optimised through evolution for copper absorption as well as copper reduction by using a proper choice of ligand chemistry and ligand geometry.

\section{Conflict of Interests}

The research in this work has been financed by the foundation for environmental strategic research, MISTRA, which is administrated by the Swedish state. In the paper, the brand names of two antifouling biocides are mentioned; Selectope and Seanine. It is hereby stated that neither of the authors 


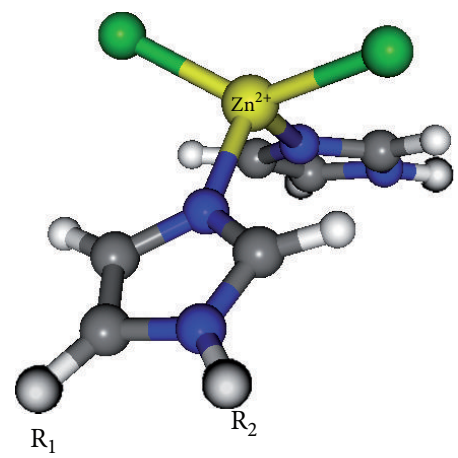

(a)

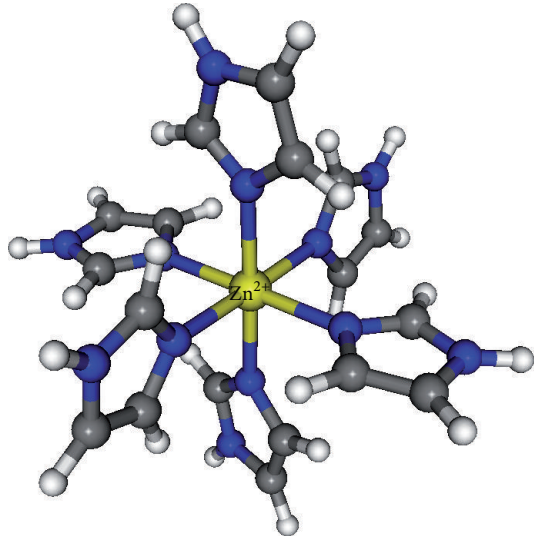

(b)

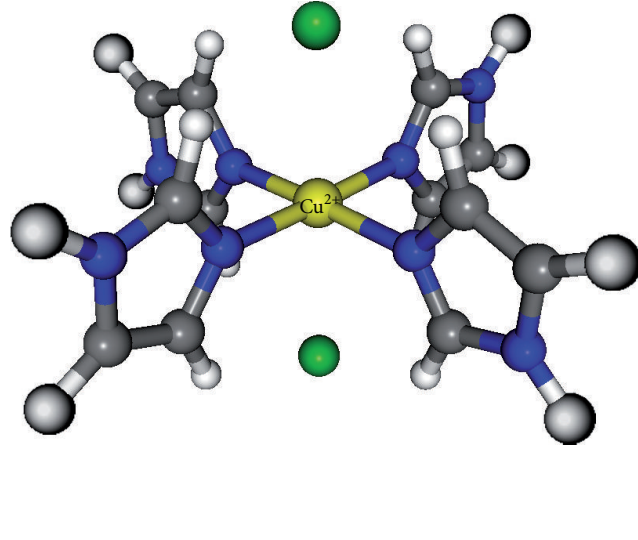

(c)

Figure 9: Coordination geometries [38]. (a) Tetrahedral $\left[\mathrm{Zn}(\mathrm{Me}-\mathrm{Im})_{2} \mathrm{Cl}_{2}\right]$, (b) octahedral $\left[\mathrm{ZnIm}_{6}\right]^{2+}$, and (c) tetragonal $\left[\mathrm{CuIm}{ }_{4} \mathrm{Cl}{ }_{2}\right]$ and $\left[\mathrm{Cu}(\mathrm{Me}-\mathrm{Im})_{4} \mathrm{Cl}_{2}\right] \cdot \mathrm{R}_{1}$ and $\mathrm{R}_{2}$ are defined as in Scheme 1 . The coordination geometry for $\mathrm{Cu}^{2+}$ complexes is tetragonal $\mathrm{D} 4 \mathrm{~h}$ symmetry for the methylated imidazoles, equivalent to unsubstituted imidazole. The imidazole ligands are almost perpendicular to the coordination axis and the chlorides are weakly bound axially [38, 154-156]. However, regarding $\mathrm{Zn}^{2+}$ complexes, unsubstituted imidazole forms octahedral complexes $[38,155]\left[\mathrm{Zn}(\mathrm{Im})_{6}\right]^{2+}$, whereas the methylated imidazoles form tetrahedral C2v complexes $[38,156,157]\left[\mathrm{Zn}\left({\mathrm{Me}-\mathrm{Im})_{2} \mathrm{Cl}}_{2}\right]\right.$ despite the large excess of imidazole ligand.

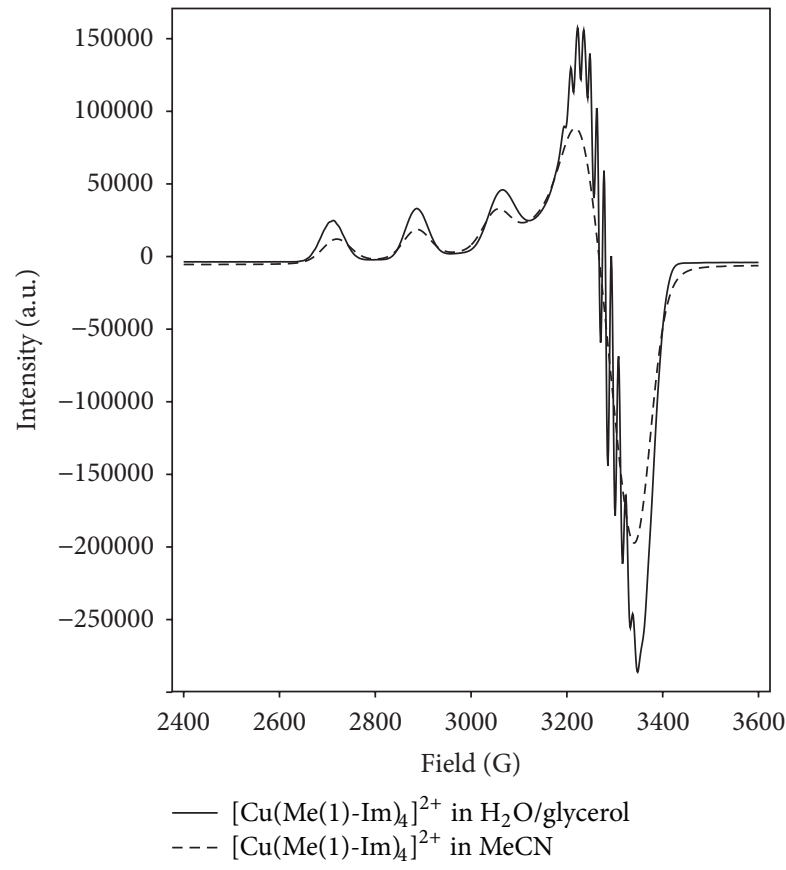

Figure 10: EPR spectra of a tetragonal Cu(II) complex with 1methylated imidazole in a mixture of water and glycerol $(-)$ and acetonitrile (- - ).

is in any financial relations with the previously mentioned commercial identities. Therefore, no conflict of interests exists.

\section{Acknowledgments}

The foundation for environmental strategic research, MISTRA, is acknowledged for financial support. The authors are also grateful to all coworkers in the Marine Paint Research Program.

\section{References}

[1] E. Almeida, T. C. Diamantino, and O. de Sousa, "Marine paints: the particular case of antifouling paints," Progress in Organic Coatings, vol. 59, no. 1, pp. 2-20, 2007.

[2] T. Backhaus and Å. Arrhenius, Marine Paint Final Report 2003 2011, U.O. Gothenburg, Gothenburg, Sweden, 2012.

[3] L. D. Chambers, K. R. Stokes, F. C. Walsh, and R. J. K. Wood, "Modern approaches to marine antifouling coatings," Surface and Coatings Technology, vol. 201, pp. 3642-3652, 2006.

[4] I. Omae, "General aspects of tin-free antifouling paints," Chemical Review, vol. 103, no. 9, pp. 3431-3448, 2003.

[5] International Maritime Organization, International Convention on the Control of Harmful Anti-fouling Systems on Ships, 2011, http://www.imo.org .

[6] I. Omae, "Organotin antifouling paints, their alternatives and marine environment," Kagaku Kogyo, vol. 54, p. 646, 2003.

[7] C. Hellio and D. Yebra, Advances in Marine Antifouling Coatings and Technologies, Woodhead Publishing, 2009.

[8] M. A. Champ and P. F. Seligman, "Research information requirements associated with the environmental fate and effects of compounds," in Organotin, pp. 601-614, 1996.

[9] M. A. Champ and P. F. Seligman, Organotin: Environmental Fate and Effects, 1996.

[10] H. Blanck and B. Dahl, "Recovery of marine periphyton communities around a Swedish marina after the ban of TBT use in antifouling paint," Marine Pollution Bulletin, vol. 36, no. 6, pp. 437-442, 1998

[11] M. Gustafsson, I. Dahllöf, H. Blanck, P. Hall, S. Molander, and K. Nordberg, "Benthic foraminiferal tolerance to tri-n-butyltin (TBT) pollution in an experimental mesocosm," Marine Pollution Bulletin, vol. 40, no. 12, pp. 1072-1075, 2000.

[12] A. Arrhenius, T. Backhaus, F. Groenvall, M. Junghans, M. Scholze, and H. Blanck, "Effects of three antifouling agents 
on algal communities and algal reproduction: mixture toxicity studies with TBT, irgarol, and sea-nine," Archives of Environmental Contamination and Toxicology, vol. 50, no. 3, pp. 335345, 2006.

[13] H. Blanck, K. M. Eriksson, F. Grönvall et al., "A retrospective analysis of contamination and periphyton PICT patterns for the antifoulant irgarol 1051, around a small marina on the Swedish west coast," Marine Pollution Bulletin, vol. 58, no. 2, pp. 230-237, 2009.

[14] B. Dahl and H. Blanck, "Toxic effects of the antifouling agent Irgarol 1051 on periphyton communities in coastal water microcosms," Marine Pollution Bulletin, vol. 32, no. 4, pp. 342-350, 1996.

[15] I. Dahllof, H. Blanck, and P. Hall, "Short-term effects of tri-nbutyl-tin on marine sediment samples using nutrient fluxes as effect indicators," Environmental Toxicology and Chemistry, vol. 18, no. 5, pp. 850-857, 1999.

[16] K. M. Eriksson, A. Antonelli, R. H. Nilsson, A. K. Clarke, and $\mathrm{H}$. Blanck, "A phylogenetic approach to detect selection on the target site of the antifouling compound irgarol in tolerant periphyton communities," Environmental Microbiology, vol. 11, no. 8, pp. 2065-2077, 2009.

[17] K. M. Eriksson, A. K. Clarke, L.-G. Franzen, M. Kuylenstierna, K. Martinez, and H. Blanck, "Community-level analysis of psbA gene sequences and irgarol tolerance in marine periphyton," Applied and Environmental Microbiology, vol. 75, no. 4, pp. 897906, 2009.

[18] P. Johansson, K. M. Eriksson, L. Axelsson, and H. Blanck, "Effects of seven antifouling compounds on photosynthesis and inorganic carbon use in sugar kelp Saccharina iatissima (Linnaeus)," Archives of Environmental Contamination and Toxicology, vol. 63, no. 3, pp. 365-377, 2012.

[19] D. George and S. van Epps, "Benzyl triazole-based aromatase inhibitors for the treatment of breast cancer," Bioact. Compd. Cl, p. 275, 2012.

[20] P. Worthington, "Sterol biosynthesis inhibiting triazole fungicides," Bioactive Heterocyclic Compound Classes, p. 129, 2012.

[21] R. Kharb, P. C. Sharma, and M. S. Yar, "Pharmacological significance of triazole scaffold," Journal of Enzyme Inhibition and Medicinal Chemistry, vol. 26, no. 1, pp. 1-21, 2011.

[22] I. P. Korbila and M. E. Falagas, "Investigational antimicrobial drugs for blood stream infections," Current Opinion in Investigational Drugs, vol. 9, no. 8, pp. 871-878, 2008.

[23] R. C. Moellering Jr., J. R. Graybill, J. E. McGowan Jr., and L. Corey, "Antimicrobial resistance prevention initiative: an update: proceedings of an expert panel on resistance," The American Journal of Medicine, vol. 120, no. 7, pp. S4-S25, 2007.

[24] M. M. Pearson, P. D. Rogers, J. D. Cleary, and S. W. Chapman, "Voriconazole: a new triazole antifungal agent," Annals of Pharmacotherapy, vol. 37, no. 3, pp. 420-432, 2003.

[25] C. W. Roberts, R. McLeod, D. W. Rice, M. Ginger, M. L. Chance, and L. J. Goad, "Fatty acid and sterol metabolism: potential antimicrobial targets in apicomplexan and trypanosomatid parasitic protozoa," Molecular and Biochemical Parasitology, vol. 126, no. 2, pp. 129-142, 2003.

[26] D. S. Schiller and H. B. Fung, "Posaconazole: an extendedspectrum triazole antifungal agent," Clinical Therapeutics, vol. 29, no. 9, pp. 1862-1886, 2007.

[27] N. Singhal, P. K. Sharma, R. Dudhe, and N. Kumar, "Recent advancement of triazole derivatives and their biological significance," Journal of Chemical and Pharmaceutical Research, vol. 3, no. 2, pp. 126-133, 2011.
[28] T. Porsbring, H. Blanck, H. Tjellström, and T. Backhaus, “Toxicity of the pharmaceutical clotrimazole to marine microalgal communities," Aquatic Toxicology, vol. 91, no. 3, pp. 203-211, 2009.

[29] i-tech marine paint, about selektope, 2012, http://www.i-tech .se/en/technology_and_product.aspx.

[30] A. Hilvarsson, C. Ohlauson, H. Blanck, and Å. Granmo, "Bioaccumulation of the new antifoulant medetomidine in marine organisms," Marine Environmental Research, vol. 68, no. 1, pp. 19-24, 2009.

[31] C. Ohlauson, K. M. Eriksson, and H. Blanck, "Short-term effects of medetomidine on photosynthesis and protein synthesis in periphyton, epipsammon and plankton communities in relation to predicted environmental concentrations," Biofouling, vol. 28, no. 5, pp. 491-499, 2012.

[32] M. Dahlström, L. G. E. Mårtensson, P. R. Jonsson, T. Arnebrant, and H. Elwing, "Surface active adrenoceptor compounds prevent the settlement of cyprid larvae of Balanus improvisus," Biofouling, vol. 16, no. 2-4, pp. 191-203, 2000.

[33] M. Nydén and K. Holmberg, "Stoppa havstulpanerna," Kemivärlden Biotech Med Kemisk Tidskrift, vol. 5, pp. 22-24, 2006.

[34] A. Lennquist, N. Asker, E. Kristiansson et al., "Physiology and mRNA expression in rainbow trout (Oncorhynchus mykiss) after long-term exposure to the new antifoulant medetomidine," Comparative Biochemistry and Physiology C, vol. 154, no. 3, pp. 234-241, 2011.

[35] A. Lennquist, M. C. Celander, and L. Foerlin, "Effects of medetomidine on hepatic EROD activity in three species of fish," Ecotoxicology and Environmental Safety, vol. 69, no. 1, pp. 74-79, 2008.

[36] A. Lennquist, A. Hilvarsson, and L. Foerlin, "Responses in fish exposed to medetomidine, a new antifouling agent," Marine Environmental Research, vol. 69, supplement 1, pp. S43-S45, 2010.

[37] A. Lennquist, L. G. E. Mårtensson Lindblad, D. Hedberg, E. Kristiansson, and L. Förlin, "Colour and melanophore function in rainbow trout after long term exposure to the new antifoulant medetomidine," Chemosphere, vol. 80, no. 9, pp. 1050-1055, 2010.

[38] M. Andersson, J. Hedin, P. Johansson, J. Nordstroem, and M. Nyden, "Coordination of imidazoles by $\mathrm{Cu}(\mathrm{II})$ and $\mathrm{Zn}$ (II) as studied by NMR relaxometry, EPR, far-FTIR vibrational spectroscopy and $\mathrm{Ab}$ initio calculations: effect of methyl substitution," Journal of Physical Chemistry A, vol. 114, no. 50, pp. 13146-13153, 2010.

[39] M. Andersson Trojer, A. Maartensson, and M. Nyden, "Replacement of H-bonded bridged water by transition metal ions in poly(1-vinylimidazole-co-methylmethacrylate) copolymers: a vibrational spectroscopy study using mid-FTIR, far-FTIR and ab initio calculations," Vibrational Spectroscopy, vol. 61, pp. 3842, 2012.

[40] C. Fant, P. Handa, and M. Nyden, "Complexation chemistry for tuning release from polymer coatings," Journal of Physical Chemistry B, vol. 110, no. 43, pp. 21808-21815, 2006.

[41] P. Handa, C. Fant, and M. Nyden, "Antifouling agent release from marine coatings-ion pair formation/dissolution for controlled release," Progress in Organic Coatings, vol. 57, no. 4, pp. 376-382, 2006.

[42] L. Shtykova, C. Fant, P. Handa et al., "Adsorption of antifouling booster biocides on metal oxide nanoparticles: effect of different metal oxides and solvents," Progress in Organic Coatings, vol. 64, no. 1, pp. 20-26, 2009. 
[43] H. Elwing, M. Dahlstrom, T. Arnebrant et al., “Test process for bioactive additives in antifouling paint, comprises quantifying binding ability of test substance to surface coating on flat sensor in aqueous medium or organic solvent 2004-1097, 526684, $20040429, " 2005$.

[44] L. S. Shtykova, D. Ostrovskii, P. Handa, K. Holmberg, and M. Nydén, "NMR diffusometry and FTIR in the study of the interaction between antifouling agent and binder in marine paints," Progress in Organic Coatings, vol. 51, no. 2, pp. 125-133, 2004.

[45] M. Nyden and C. Fant, "Method and use of nanoparticles to bind biocides in paints 2006-SE318, 2006096128, 20060313," 2006.

[46] M. Nyden, C. Fant, K. Holmberg, and L. Swanson, "Method and use of acidified modified polymers to bind biocides in paints 2006-372522, 7531581, 20060310," 2009.

[47] M. Andersson, O. Hansson, L. Oehrstroem, A. Idstroem, and M. Nyden, "Vinylimidazole copolymers: coordination chemistry, solubility, and cross-linking as function of $\mathrm{Cu}^{2+}$ and $\mathrm{Zn}^{2+}$ complexation," Colloid and Polymer Science, vol. 289, no. 12, pp. 1361-1372, 2011.

[48] M. Andersson Trojer, D. Isaksson, and M. Nydén, "Synthesis and polymerisation of maleoyl-L-histidine monomers and addition of histidine to an ethylene-alt-maleic co-polymer," Journal of Polymer Research, vol. 19, Article ID 9821, 2012.

[49] J. Hedin, D. Isaksson, M. Andersson, and M. Nydén, "Bi-layer formation of imidazole-modified ethyl(hydroxyethyl)cellulose at a hydrophobic surface as monitored by QCM-D," Journal of Colloid and Interface Science, vol. 336, no. 2, pp. 388-392, 2009.

[50] A. Movahedi, N. Kann, K. Moth-Paulsen, and B. M. Nyden, "Synthesis of chelating $\mathrm{Cu}(\mathrm{I})$ stabilizing polymeric ligands".

[51] Marine Paint Annual Report 2008, Gothenburg, Sweden, 2009.

[52] L. Nordstierna, A. A. Abdalla, M. Masuda, G. Skarnemark, and M. Nydén, "Molecular release from painted surfaces: free and encapsulated biocides," Progress in Organic Coatings, vol. 69, no. 1, pp. 45-48, 2010.

[53] "Polymeric core-shell particles: physicochemical properties and controlled release," in Encyclopedia of Surface and Colloid Science, P. Somasundaran, Ed., Taylor and Francis, New York, NY, USA, 2013.

[54] J. Bergek, M. Andersson Trojer, A. Mok, and L. Nordstierna, "Controlled release of microencapsulated 2-n-octyl4-isothiazolin-3-one from coatings: effect of macroscopic and microscopic pores," Colloids and Surfaces A. In press.

[55] J. Bergek, M. Andersson Trojer, H. Uhr, and L. Nordstierna, "Controlled release of microencapsulated 2-n-octyl-4-isothiazolin-3-one from coatings: polyelectrolyte multilayers as a global a rate-determining barrier," Journal of Materials Chemistry B. Submitted.

[56] A. Enejder, F. Svedberg, L. Nordstierna, and M. Nydén, "Chemical release from single PMMA microparticles monitored by CARS microscopy," in Multiphoton Microscopy in the Biomedical Sciences, Proceedings of SPIE, January 2011.

[57] L. Nordstierna, A. A. Abdalla, M. Nordin, and M. Nydén, “Comparison of release behaviour from microcapsules and microspheres," Progress in Organic Coatings, vol. 69, no. 1, pp. 49-51, 2010.

[58] L. Nordstierna, A. Movahedi, and M. Nydén, "New route for microcapsule synthesis," Journal of Dispersion Science and Technology, vol. 32, no. 3, pp. 310-311, 2011.
[59] B. M. Nyden, L. O. Nordstierna, E. M. Bernad, and A. M. A. A. Abdalla, "Slow releasing microcapsules and microspheres comprising an biocidal substance," 2010-EP56735, 2010133548, 20100517, 2010.

[60] M. Andersson Trojer, L. Nordstierna, M. Nordin, B. M. Nyden, and K. Holmberg, "Physical Chemistry chemical physics," Encapsulation of Actives For Controlled Release, 2013.

[61] M. Andersson Trojer, H. Andersson, Y. Li et al., "Charged microcapsules for controlled release of hydrophobic actives. Part III: the effect of polyelectrolyte brush- and multilayers on sustained release," Physical Chemistry Chemical Physics, vol. 15, no. 17, pp. 6456-6466, 2013.

[62] M. Andersson Trojer, K. Holmberg, and M. Nydén, "The importance of proper anchoring of an amphiphilic dispersant for colloidal stability," Langmuir, vol. 28, no. 9, pp. 4047-4050, 2012.

[63] M. A. Trojer, Y. Li, C. Abrahamsson et al., "Charged microcapsules for controlled release of hydrophobic actives. Part I: encapsulation methodology and interfacial properties," Soft Matter, vol. 9, no. 5, pp. 1468-1477, 2013.

[64] M. Andersson Trojer, Y. Li, M. Wallin, K. Holmberg, and M. Nyden, "Charged microcapsules for controlled release of hydrophobic actives Part II: surface modification by LbL adsorption and lipid bilayer formation on properly anchored dispersant layers," Journal of Colloid and Interface Science, vol. 409, no. 1, pp. 8-17, 2013.

[65] M. Andersson Trojer, A. Mohamed, and J. Eastoe, "A highly hydrophobic anionic surfactant at the oil-water, water-polymer and oil-polymer interfaces: implications on spreading coefficients, polymer interactions and microencapsulation via internal phase separation," Colloids and Surfaces A, vol. 436, no. 5, pp. 1048-1059, 2013.

[66] M. A. Trojer, A. Wendel, K. Holmberg, and M. Nydén, “The effect of $\mathrm{pH}$ on charge, swelling and desorption of the dispersant poly(methacrylic acid) from poly(methyl methacrylate) microcapsules," Journal of Colloid and Interface Science, vol. 375, no. 1, pp. 213-215, 2012.

[67] E. Ytreberg, J. Karlsson, and B. Eklund, "Comparison of toxicity and release rates of $\mathrm{Cu}$ and $\mathrm{Zn}$ from anti-fouling paints leached in natural and artificial brackish seawater," Science of the Total Environment, vol. 408, no. 12, pp. 2459-2466, 2010.

[68] S. R. Nadella, J. L. Fitzpatrick, N. Franklin, C. Bucking, S. Smith, and C. M. Wood, "Toxicity of dissolved $\mathrm{Cu}, \mathrm{Zn}, \mathrm{Ni}$ and $\mathrm{Cd}$ to developing embryos of the blue mussel (Mytilus trossolus) and the protective effect of dissolved organic carbon," Comparative Biochemistry and PhysiologyC, vol. 149, no. 3, pp. 340-348, 2009.

[69] S. Niyogi and C. M. Wood, "Biotic ligand model, a flexible tool for developing site-specific water quality guidelines for metals," Environmental Science and Technology, vol. 38, no. 23, pp. 61776192,2004

[70] A. Viarengo, M. Pertica, G. Mancinelli, B. Burlando, L. Canesi, and M. Orunesu, "In vivo effects of copper on the calcium homeostasis mechanisms of mussel gill cell plasma membranes," Comparative Biochemistry and Physiology, vol. 113, no. 3, pp. 421-425, 1996.

[71] L. Ciavatta, D. Ferri, and R. Palombari, "On the equilibrium $\mathrm{Cu}^{2+}+\mathrm{Cu}(\mathrm{s}) \rightleftarrows 2 \mathrm{Cu}^{+}$," Journal of Inorganic and Nuclear Chemistry, vol. 42, no. 4, pp. 593-598, 1980.

[72] M. G. Simmons, C. L. Merrill, L. J. Wilson, L. A. Bottomley, and K. M. Kadish, "The Bis-2,6-[1-(2-imidazol-4-ylethylimino)ethyl]pyridinecopper(I) cation. A synthetic CuI oxygen carrier in solution as a potential model for oxyhemocyanin," 
Journal of the Chemical Society, Dalton Transactions, no. 10, pp. 1827-1837, 1980.

[73] L. Kiaune and N. Singhasemanon, "Pesticidal copper (I) oxide: environmental fate and aquatic toxicity," Reviews of Environmental Contamination and Toxicology, vol. 213, pp. 1-26, 2011.

[74] S. J. Brooks and M. Waldock, "The use of copper as a biocide in marine antifouling paints," in Advances in Marine Antifouling Coatings and Technologies, pp. 492-521, 2009.

[75] E. Cotou, M. Henry, C. Zeri, G. Rigos, A. Torreblanca, and V. A. Catsiki, "Short-term exposure of the European sea bass Dicentrarchus labrax to copper-based antifouling treated nets: copper bioavailability and biomarkers responses," Chemosphere, vol. 89, no. 9, pp. 1091-1097, 2012.

[76] T. R. Chan, R. Hilgraf, K. B. Sharpless, and V. V. Fokin, "Polytriazoles as copper(I)-stabilizing ligands in catalysis," Organic Letters, vol. 6, no. 17, pp. 2853-2855, 2004.

[77] Y. Rondelez, M.-N. Rager, A. Duprat, and O. Reinaud, "Calix[6]arene-based cuprous "funnel complexes": a mimic for the substrate access channel to metalloenzyme active sites," Journal of the American Chemical Society, vol. 124, no. 7, pp. 1334-1340, 2002.

[78] Y. Rondelez, G. Bertho, and O. Reinaud, "The first water-soluble copper(I) calix[6]arene complex presenting a hydrophobic ligand binding pocket: a remarkable model for active sites in metalloenzymes," Angewandte Chemie International Edition, vol. 41, no. 6, pp. 1044-1046, 2002.

[79] T. Vänngård, H. M. Swartz, J. R. Bolton, and D. C. Borg, Applications of Electron Spin Resonance, John Wiley and Sons, New York, NY, USA, 1972.

[80] M. Brändén, A. Namslauer, Ö. Hansson, R. Aasa, and P. Brzezinski, "Water-hydroxide exchange reactions at the catalytic site of heme-copper oxidases," Biochemistry, vol. 42, no. 45, pp. 1317813184, 2003.

[81] M. M. Ivkovic-Jensen, G. M. Ullmann, S. Young et al., "Effects of single and double mutations in plastocyanin on the rate constant and activation parameters for the rearrangement gating the electron-transfer reaction between the triplet state of zinc cytochrome c and cupriplastocyanin," Biochemistry, vol. 37, no. 26, pp. 9557-9569, 1998.

[82] F. Jacobson, A. Pistorius, D. Farkas et al., "pH dependence of copper geometry, reduction potential, and nitrite affinity in nitrite reductase," Journal of Biological Chemistry, vol. 282, no. 9, pp. 6347-6355, 2007.

[83] H. Jansson and O. Hansson, "Competitive inhibition of electron donation to photosystem 1 by metal-substituted plastocyanin," Biochimica Et Biophysica Acta, vol. 1777, no. 9, pp. 1116-1121, 2008.

[84] H. Jansson, M. Oekvist, F. Jacobson, M. Ejdebaeck, O. Hansson, and L. Sjoelin, "The crystal structure of the spinach plastocyanin double mutant G8D/L12E gives insight into its low reactivity towards photosystem 1 and cytochrome f," Biochimica et Biophysica Acta, vol. 1607, no. 2-3, pp. 203-210, 2003.

[85] D. La Mendola, R. P. Bonomo, S. Caminati et al., "Copper(II) complexes with an avian prion $\mathrm{N}$-terminal region and their potential SOD-like activity," Journal of Inorganic Biochemistry, vol. 103, no. 2, pp. 195-204, 2009.

[86] D. La Mendola, D. Farkas, F. Bellia et al., "Probing the copper(II) binding features of angiogenin. Similarities and differences between a $\mathrm{N}$-terminus peptide fragment and the recombinant human protein," Inorganic Chemistry, vol. 51, no. 1, pp. 128-141, 2012.
[87] D. La Mendola, A. Magrì, T. Campagna et al., "A doppel $\alpha$-helix peptide fragment mimics the copper(II) interactions with the whole protein," Chemistry, vol. 16, no. 21, pp. 6212-6223, 2010.

[88] D. L. Mendola, A. Magrì, L. I. Vagliasindi, Ö. Hansson, R. P. Bonomo, and E. Rizzarelli, "Copper(II) complex formation with a linear peptide encompassing the putative cell binding site of angiogenin," Dalton Transactions, vol. 39, no. 44, pp. 1067810684, 2010.

[89] D. L. Mendola, A. Magrì, Ö. Hansson, R. P. Bonomo, and E. Rizzarelli, "Copper(II) complexes with peptide fragments encompassing the sequence 122-130 of human doppel protein," Journal of Inorganic Biochemistry, vol. 103, no. 5, pp. 758-765, 2009.

[90] S. Modi, M. Nordling, L. G. Lundberg, O. Hansson, and D. S. Bendall, "Reactivity of cytochromes $\mathrm{c}$ and $\mathrm{f}$ with mutant forms of spinach plastocyanin," Biochimica et Biophysica Acta, vol. 1102, no. 1, pp. 85-90, 1992.

[91] K. Olesen, M. Ejdeback, and O. Hansson, "Electron transfer from genetically modified plastocyanin to photosystem 1," in Proceedings of the 11th International photosynthesis: Photosynthesis mechanisms and effects Congress, pp. 1597-1600, 1998.

[92] K. Sigfridsson, M. Ejdeback, and M. Sundahl, "Electron transfer in ruthenium-modified spinach plastocyanin mutants," Archives of Biochemistry and Biophysics, vol. 351, no. 2, pp. 197206, 1998.

[93] K. Sigfridsson, S. Young, and O. Hansson, "Electron transfer between spinach plastocyanin mutants and photosystem 1," European Journal of Biochemistry, vol. 245, no. 3, p. 805, 1998.

[94] Y. Xue, M. Okvist, O. Hansson, and S. Young, "Crystal structure of spinach plastocyanin at 1.7 A resolution," Protein Science, vol. 7, no. 10, pp. 2099-2105, 1998.

[95] R. J. Sundberg and R. B. Martin, "Interactions of histidine and other imidazole derivatives with transition metal ions in chemical and biological systems," Chemical Reviews, vol. 74, no. 4, pp. 471-517, 1974.

[96] C. J. Jones, D- and F-Block Chemistry, The Royal Society of Chemistry, Birmingham, England, 2001.

[97] B. N. Figgis and M. A. Hitchman, "Ligand field theory and its applications," Journal of Chemical Education, vol. 79, no. 9, p. 1072, 2002.

[98] R. G. Pearson, "Hard and soft acids and bases," Journal of the American Chemical Society, vol. 85, no. 22, pp. 3533-3539, 1963.

[99] R. G. Pearson, "Absolute electronegativity and hardness correlated with molecular orbital theory," Proceedings of the National Academy of Sciences of the USA, vol. 83, no. 22, pp. 8440-8441, 1986.

[100] R. H. Crabtree, The Organometallic Chemistry of the Transition Metals, John Wiley and Sons, New York, NY, USA, 4th edition, 2005.

[101] Y. Jean, Molecular Orbitals of Transition Metal Complexes, Oxford University Press, New York, NY, USA, 2005.

[102] K. Liu, W. Shi, and P. Cheng, "The coordination chemistry of $\mathrm{Zn}(\mathrm{II}), \mathrm{Cd}(\mathrm{II})$ and $\mathrm{Hg}(\mathrm{II})$ complexes with 1,2,4-triazole derivatives," Dalton Transactions, vol. 40, no. 34, pp. 8475-8490, 2011.

[103] W. Ouellette, S. Jones, and J. Zubieta, "Solid state coordination chemistry of metal-1,2,4-triazolates and the related metal-4pyridyltetrazolates," CrystEngComm, vol. 13, no. 14, pp. 44574485, 2011.

[104] J. G. Haasnoot, "Mononuclear, oligonuclear and polynuclear metal coordination compounds with 1, 2, 4-triazole derivatives 
as ligands," Coordination Chemistry Reviews, vol. 200-202, pp. 131-185, 2000.

[105] J. P. Zhang, Y. B. Zhang, J. B. Lin, and X. M. Chen, "Metal azolate frameworks: from crystal engineering to functional materials," Chemical Reviews, vol. 112, no. 2, pp. 1001-1033, 2012.

[106] R. G. Pearson, "Hard and soft acids and bases," Journal of the American Chemical Society, vol. 85, no. 22, pp. 3533-3539, 1963.

[107] L. M. Epstein, D. K. Straub, and C. Maricondi, "Mossbauer spectra of some porphyrin complexes with pyridine, piperidine, and imidazole," Inorganic Chemistry, vol. 6, no. 9, pp. 1720-1724, 1967.

[108] N. S. Rannulu, R. Amunugama, Z. Yang, and M. T. Rodgers, "Influence of $\mathrm{s}$ and $\mathrm{d}$ orbital occupation on the binding of metal ions to imidazole," Journal of Physical Chemistry A, vol. 108, no. 30, pp. 6385-6396, 2004.

[109] D. Reddy, K. J. Akerman, M. P. Akerman, and D. Jaganyi, "A kinetic investigation into the rate of chloride substitution from chloro terpyridine platinum(II) and analogous complexes by a series of azole nucleophiles," Transition Metal Chemistry, vol. 36, no. 6, pp. 593-602, 2011.

[110] B. Barszcz, M. Gabryszewski, J. Kulig, and B. Lenarcik, "Potentiometric studies on complexes of silver(I) in solutions. Part 2. Correlation between the stability of the silver(I)-azole complexes and the ligand basicity," Journal of the Chemical Society, Dalton Transactions, no. 10, pp. 2025-2028, 1986.

[111] D. Hourdet, J. A. Gadgil, K. Podhajecka, M. V. Badiger, A. Brûlet, and P. P. Wadgaonkar, "Thermoreversible behavior of associating polymer solutions: thermothinning versus thermothickening," Macromolecules, vol. 38, no. 20, pp. 8512-8521, 2005.

[112] M. Prabaharan and J. F. Mano, "Chitosan derivatives bearing cyclodextrin cavitiesas novel adsorbent matrices," Carbohydrate Polymers, vol. 63, no. 2, pp. 153-166, 2006.

[113] R. Souzy, B. Ameduri, B. Boutevin, G. Gebel, and P. Capron, "Functional fluoropolymers for fuel cell membranes," Solid State Ionics, vol. 176, no. 39-40, pp. 2839-2848, 2005.

[114] M. M. Nasef and E. S. A. Hegazy, "Preparation and applications of ion exchange membranes by radiation-induced graft copolymerization of polar monomers onto non-polar films," Progress in Polymer Science, vol. 29, no. 6, pp. 499-561, 2004.

[115] Q. Chen and B.-H. Han, "Prepolymerization and postpolymerization functionalization approaches to fluorescent conjugated carbazole-based glycopolymers via click chemistry," Journal of Polymer Science A, vol. 47, no. 11, pp. 2948-2957, 2009.

[116] M. A. Gauthier, M. I. Gibson, and H. A. Klok, "Synthesis of functional polymers by post-polymerization modification," Angewandte Chemie International Edition, vol. 48, no. 1, pp. 4858, 2008.

[117] R. Huisgen, "1,3-Dipolar cycloadditions," Proceedings of the Chemical Society, pp. 357-369, 1961.

[118] V. V. Rostovtsev, L. G. Green, V. V. Fokin, and K. B. Sharpless, "A stepwise Huisgen cycloaddition process: copper(I)-catalyzed regioselective, "ligation" of azides and terminal alkynes," Angewandte Chemie International, vol. 41, no. 14, pp. 2596-2599, 2002.

[119] B. C. Boren, S. Narayan, L. K. Rasmussen et al., "Rutheniumcatalyzed azide-alkyne cycloaddition: scope and mechanism," Journal of the American Chemical Society, vol. 130, no. 28, pp. 8923-8930, 2008.

[120] D. Braun and F. Hu, "Polymers from non-homopolymerizable monomers by free radical processes," Progress in Polymer Science, vol. 31, no. 3, pp. 239-276, 2006.
[121] R. C. P. Cubbon, "The free radical and anionic polymerization of some N-substituted maleimides," Polymer, vol. 6, no. 8, pp. 419-426, 1965.

[122] D. J. T. Hill, L. Y. Shao, P. J. Pomery, and A. K. Whittaker, "The radical homopolymerization of N-phenylmaleimide, N-nhexylmaleimide and N-cyclohexylmaleimide in tetrahydrofuran," Polymer, vol. 42, no. 11, pp. 4791-4802, 2001.

[123] C. Hulubei and S. Morariu, "Synthesis and radical polymerization of N-(3-acetyl-4-carboxy-phenyl)-maleimide," High Performance Polymers, vol. 12, no. 4, pp. 525-533, 2000.

[124] T. Oishi, H. Nagata, and H. Tsutsumi, "Synthesis and polymerization of N-substituted maleimides based on L-alanine ester," Polymer, vol. 39, no. 17, pp. 4135-4146, 1998.

[125] T. M. Pyriadi and A. S. Hamad, "Preparation of new copolymers of vinyl acetate and N-substituted maleimides," Polymer, vol. 37, no. 23, pp. 5283-5287, 1996.

[126] P. O. Tawney, R. H. Snyder, C. E. Bryan et al., "The chemistry of maleimide and its derivatives. I. N-carbamylmaleimide," Journal of Organic Chemistry, vol. 25, no. 1, pp. 56-60, 1960.

[127] P. O. Tawney, R. H. Snyder, R. P. Conger, K. A. Leibbrand, C. H. Stiteler, and A. R. Williams, "The chemistry of maleimide and its derivatives. II. Maleimide and N-methylolmaleimide," Journal of Organic Chemistry, vol. 26, no. 1, pp. 15-21, 1961.

[128] J. Z. Yang and T. Otsu, "Reactivities of citraconic anhydride, $\mathrm{N}$-alkylcitraconimides, dialkyl citraconates and dialkyl mesaconates in radical copolymerization with vinyl acetate and characterization of the resulting copolymers," European Polymer Journal, vol. 27, no. 10, pp. 1081-1086, 1991.

[129] J. M. G. Cowie, Polymers: Chemistry and Physics of Modern Materials, CRC Press, 2nd edition, 1991.

[130] K. H. Wu, T. C. Chang, Y. T. Wang, Y. S. Hong, and T. S. Wu, "Interactions and mobility of copper(II)-imidazole-containing copolymers," European Polymer Journal, vol. 39, no. 2, pp. 239245, 2003.

[131] N. L. Mazyar, V. V. Annenkov, V. A. Kruglova et al., "Acid-base properties of poly(1-vinylazoles) in aqueous solution," Russian Chemical Bulletin, vol. 49, no. 12, pp. 2013-2017, 2000.

[132] E. N. Danilovtseva, M. A. Chafeev, and V. V. Annenkov, "New polyelectrolytes based on 4-vinyl-1,2,3-triazole and 1vinylimidazole," Journal of Polymer Science A, vol. 50, no. 8, pp. 1539-1546, 2012.

[133] H. C. Kolb, M. G. Finn, and K. B. Sharpless, "Click chemistry: diverse chemical function from a few good reactions," Angewandte Chemie International Edition, vol. 40, no. 11, pp. 20042021, 2001.

[134] R. J. Thibault, K. Takizawa, P. Lowenheilm et al., "A versatile new monomer family: functionalized 4-vinyl-1,2,3-triazoles via click chemistry," Journal of the American Chemical Society, vol. 128, no. 37, pp. 12084-12085, 2006.

[135] L. A. Belfiore and M. P. McCurdie, "Reactive blending via metalligand coordination," Journal of Polymer Science B, vol. 33, no. 1, pp. 105-124, 1995.

[136] L. A. Belfiore, M. P. McCurdie, and P. K. Das, "Macromoleculemetal complexes: ligand field stabilization and thermophysical property modification," Polymer, vol. 42, no. 25, pp. 999510006, 2001.

[137] T. Kaliyappan and P. Kannan, "Co-ordination polymers," Progress in Polymer Science, vol. 25, no. 3, pp. 343-370, 2000.

[138] R. Hoogenboom, D. Fournier, and U. S. Schubert, "Asymmetrical supramolecular interactions as basis for complex responsive macromolecular architectures," Chemical Communications, no. 2, pp. 155-162, 2008. 
[139] V. Marin, E. Holder, R. Hoogenboom, and U. S. Schubert, "Functional ruthenium(II)- and iridium(III)-containing polymers for potential electro-optical applications," Chemical Society Reviews, vol. 36, no. 4, pp. 6618-6635, 2007.

[140] C. S. K. Mak and W. K. Chan, "Electroluminescence from metalcontaining polymers and metal complexes with functional ligands," in Highly Efficient OLEDs With Phosphorescent Materials, p. 329, 2008.

[141] H. K. Reimschuessel, "Polymer-metal halide interactions: nylon 6-zirconium tetrafluoride system," Colloid and Polymer Science, vol. 260, no. 9, pp. 842-850, 1982.

[142] M. Sato, K. Kondo, and K. Takemoto, "Functional monomers and polymers, 43. ESR study on the copper(II) complexes of polymers containing imidazolyl groups and of their monomeric analogs," Die Makromolekulare Chemie, vol. 179, no. 3, pp. 601610,1978

[143] M. Sato, K. Kondo, and K. Takemoto, "Functional monomers and polymers, 56. Effects of ionic strength on the structure of $\mathrm{Cu}(\mathrm{II})$. poly(vinylimidazole) and $\mathrm{Cu}(\mathrm{II})$. imidazole complexes in aqueous solution," Die Makromolekulare Chemie, vol. 180, no. 3, pp. 699-704, 1979.

[144] M. Sato, K. Kondo, and K. Takemoto, "ESR studies on the dimer formation between copper ions in the poly(vinylimidazole) copper(II) complex," Polymer Bulletin, vol. 2, no. 5, pp. 305-308, 1980.

[145] A. B. Strong, Plastics: Materials and Processing, Pearson Education, New Jersey, NJ, USA, 3rd edition, 2006.

[146] V. A. Berstein and V. M. Egorov, Differential Scanning Calorimetry of Polymers, Ellis Horwood, Chichester, UK, 1994.

[147] H. Tanaka, S. Tai, K. Kamijima et al., "Antifouling paint containing compounds to improve viscosity stability and durability of films in seawater 1994-309674, 659848, 19941222," 1995.

[148] U. Gerigk and D. Ventur, "Preparation of thiadiazole compounds as antifouling agents 1992-4230955, 19920916," 1994.

[149] M. Mechtel, W. Podszun, and K. H. Kaesler, "Antifouling agents and coatings and their preparation 1997-EP5626, 9817732, 19971013," 1998.

[150] F. Kunisch, M. Kugler, H. Schrage, and H. L. Elbe, "Antifouling agents comprising benzothiophene-2-carboxamide S, S-dioxide derivs 1995-19534868, 19950920," 1997.

[151] R. Neiman and D. Kivelson, "ESR line shapes in glasses of copper complexes," The Journal of Chemical Physics, vol. 35, no. 1, pp. 149-155, 1961.

[152] F. Jiang, J. McCracken, and J. Peisach, "Nuclear quadrupole interactions in copper(II)-diethylenetriamine-substituted imidazole complexes and in copper(II) proteins," Journal of the American Chemical Society, vol. 112, no. 25, pp. 9035-9044, 1990.

[153] H. J. Scholl and J. Huettermann, "ESR and ENDOR of copper(II) complexes with nitrogen donors: probing parameters for prosthetic group modeling of superoxide dismutase," Journal of Physical Chemistry, vol. 96, no. 24, pp. 9684-9691.

[154] C.-C. Su, H. C. Jan, H. Kuo-Yih et al., "Bonding properties of $\mathrm{Cu}(\mathrm{II})$-imidazole chromophores: spectroscopic and electrochemical properties of monosubstituted imidazole copper(II) complexes. Molecular structure of [ $\mathrm{Cu}(4$-methylimidazole $) 4\left(\mathrm{ClO}_{4}\right)_{2}$ ]," Inorganica Chimica Acta, vol. 196, no. 2, pp. 231-240, 1992.

[155] B. C. Cornilsen and K. Nakamoto, "Metal isotope effect on metal-ligand vibrations-XII: imidazole complexes with $\mathrm{Co}(\mathrm{II})$, $\mathrm{Ni}(\mathrm{II}), \mathrm{Cu}(\mathrm{II})$ and $\mathrm{Zn}(\mathrm{II})$, , Journal of Inorganic and Nuclear Chemistry, vol. 36, no. 11, pp. 2467-2471, 1974.
[156] J. Reedijk, "Pyrazoles and imidazoles as ligands. II. Coordination compounds of N-methyl imidazole with metal perchlorates and tetrafluoroborates," Inorganica Chimica Acta, vol. 3, pp. 517$522,1969$.

[157] C. Perchard and A. Novak, "The low-frequency infrared and Raman spectra of ammonia and imidazole complexes of zinc(II) halides," Spectrochimica Acta A, vol. 26, no. 4, pp. 871-881, 1970.

[158] A. B. P. Lever, "Electrochemical parametrization of metal complex redox potentials, using the ruthenium(III)/ruthenium(II) couple to generate a ligand electrochemical series," Inorganic Chemistry, vol. 29, no. 6, pp. 1271-1285, 1990.

[159] S. Ahrland, K. Nilsson, and B. Tagesson, "Thermodynamics of the copper(I) halide and thiocyanate complex formation in acetonitrile," Acta Chemica Scandinavica A, vol. 37, pp. 193-201, 1983.

[160] R. R. Bessette and J. W. Olver, "Measurement of diffusion coefficients for the reduction of copper(I) and (II) in acetonitrile," Journal of Electroanalytical Chemistry and Interfacial Electrochemistry, vol. 21, no. 3, pp. 525-529, 1969.

[161] D. C. Gould and A. Ehrenberg, " $\mathrm{Cu}^{2+}$ in non axial-field: a model for $\mathrm{Cu}^{2+}$ in copper enzymes," European Journal of Biochemistry, vol. 5, no. 4, pp. 451-455, 1968.

[162] J. T. Rubino and K. J. Franz, "Coordination chemistry of copper proteins: how nature handles a toxic cargo for essential function," Journal of Inorganic Biochemistry, vol. 107, no. 1, pp. 129$143,2012$.

[163] J. L. Dalsin and P. B. Messersmith, "Bioinspired antifouling polymers," Materials Today, vol. 8, no. 9, pp. 38-46, 2005. 

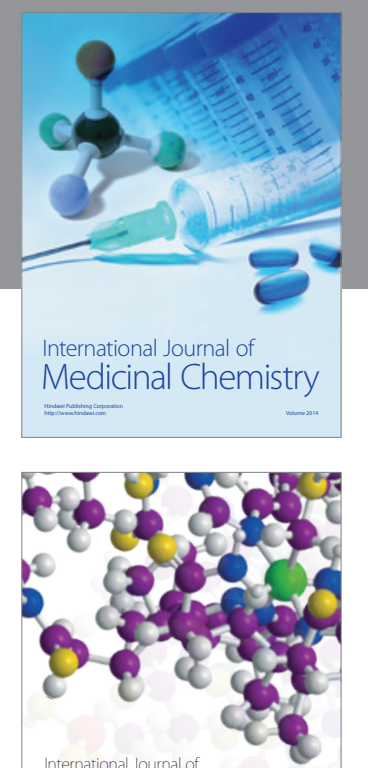

\section{Carbohydrate} Chemistry

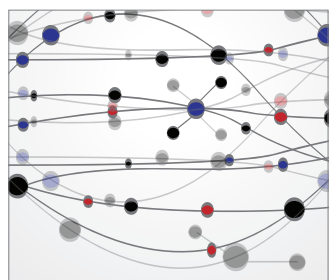

The Scientific World Journal
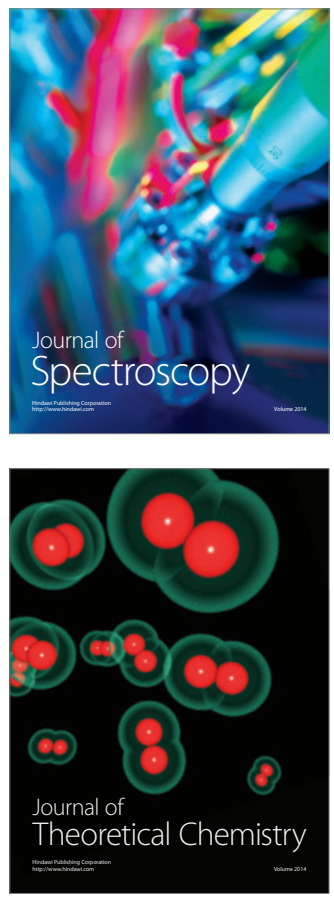
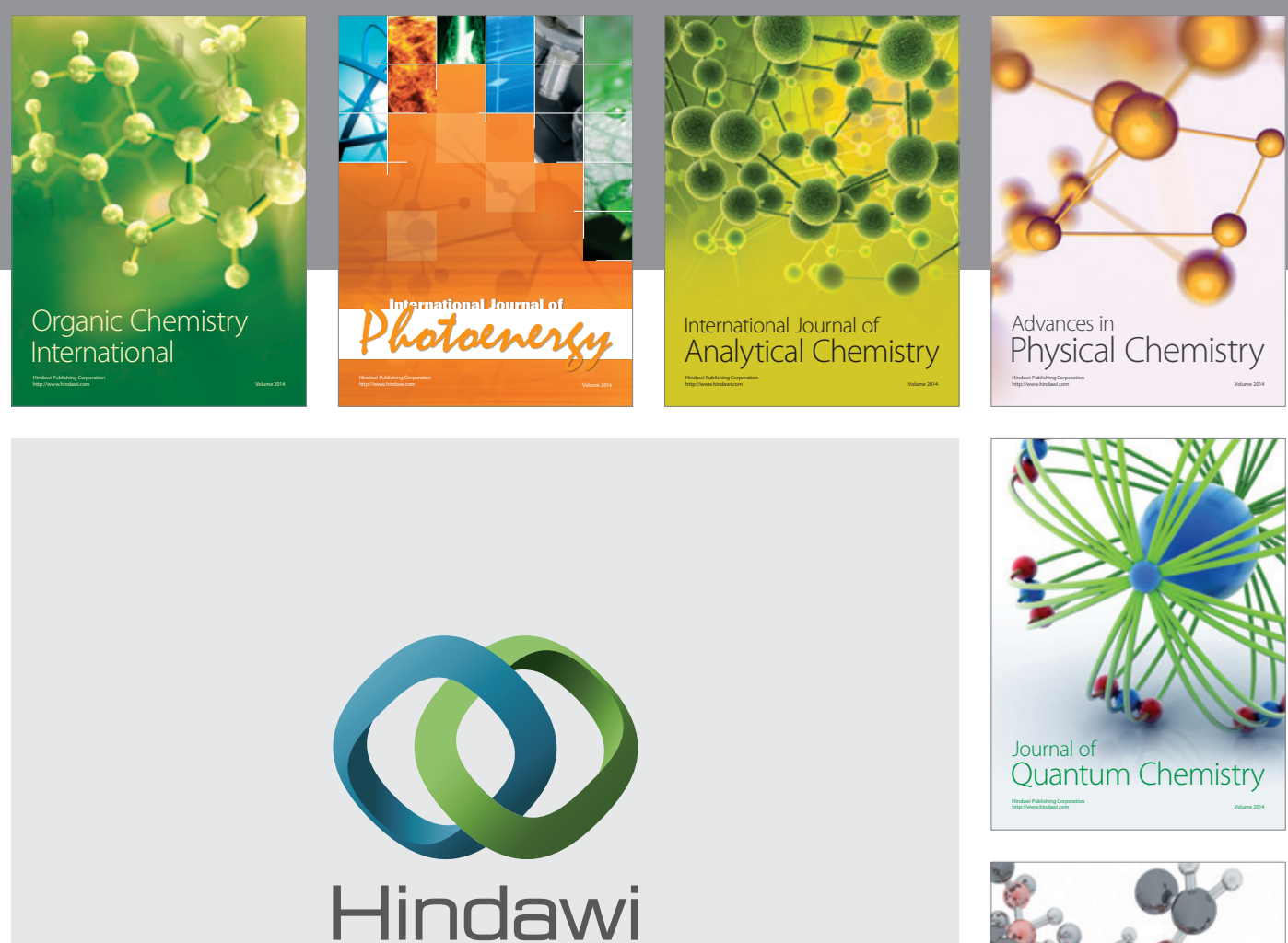

Submit your manuscripts at

http://www.hindawi.com

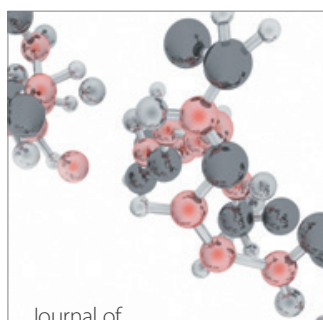

Analytical Methods

in Chemistry

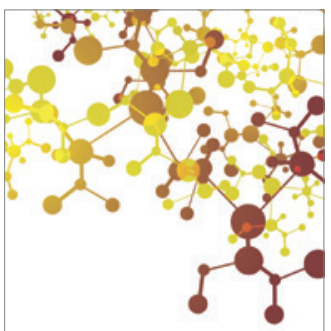

Journal of

Applied Chemistry

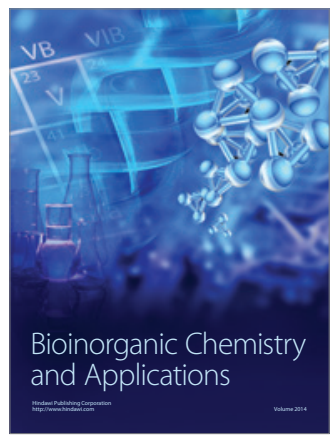

Inorganic Chemistry
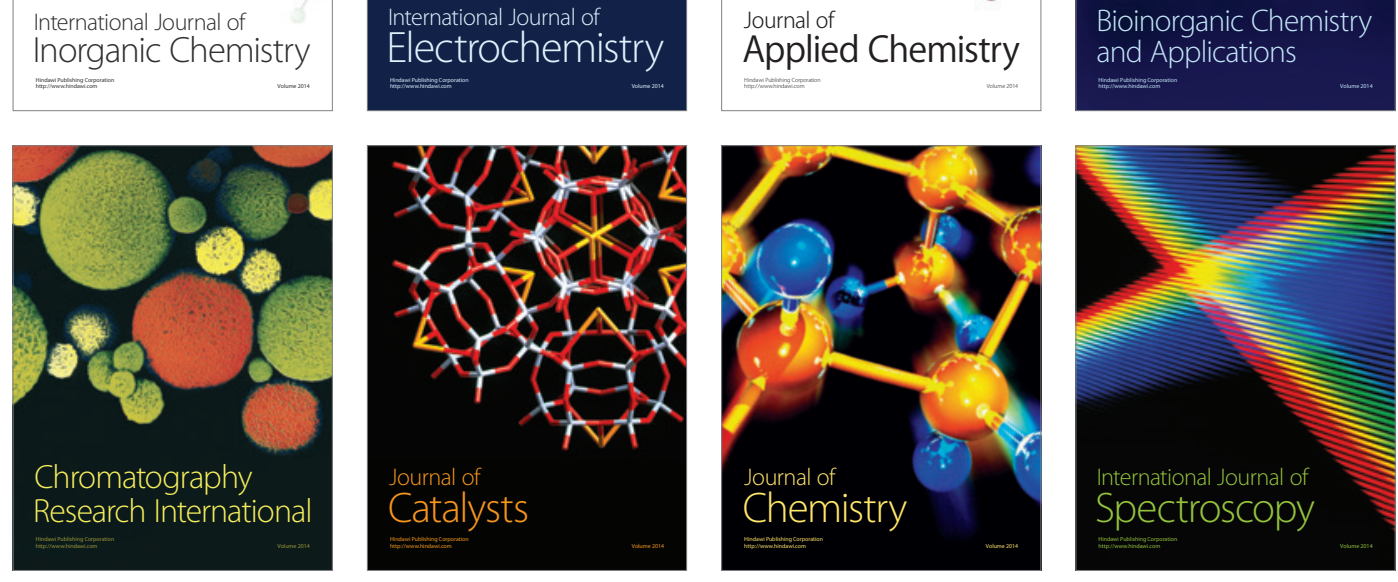